\title{
Shape Memory Alloy-Reinforced Metal-Matrix Composites: A Review
}

\author{
D. R. Ni • Z. Y. Ma
}

Received: 20 September 2014/Revised: 1 October 2014/Published online: 16 October 2014

(C) The Chinese Society for Metals and Springer-Verlag Berlin Heidelberg 2014

\begin{abstract}
Metal-matrix composites reinforced with shape memory alloys (SMA, including long fiber, short fiber, and particle) are "intelligent materials" with many special physical and mechanical properties, such as high damping property, high tensile strength, and fatigue resistance. In this review article, the fabrication method, microstructure, interface reaction, modeling, and physical and mechanical properties of the composites are addressed. Particular emphasis has been given to (a) fabrication and microstructure of aluminum matrix composites reinforced with SMAs, and (b) shape memory effect on the physical and mechanical properties of the composites. While the bulk of the information is related to aluminum matrix composites, important results are now available for other metal-matrix composites.
\end{abstract}

KEY WORDS: Metal-matrix composites; Shape memory alloy; Fabrication method; Microstructure; Interface reaction; Mechanical properties

\section{Introduction}

Metal-matrix composites (MMCs) are attractive materials for automotive, aerospace, and many other applications due to their superior mechanical and/or physical properties [1-3]. Among them, aluminum matrix composites (AMCs) are more competitive due to low density, ease to produce with relatively low cost. The reinforcements of MMCs, including continuous (long fiber) and discontinuous (short fiber, whisker, and particle) ones, mainly take advantage of their mechanical properties such as high elastic modulus, high strength, and high stiffness, and most of these reinforcements are ceramic materials such as $\mathrm{SiC}, \mathrm{Al}_{2} \mathrm{O}_{3}$, and so on. However, there is another kind of reinforcements for

Available online at http://link.springer.com/journal/40195

D. R. Ni · Z. Y. Ma ( $\square)$

Shenyang National Laboratory for Materials Science, Institute of

Metal Research, Chinese Academy of Sciences, Shenyang

110016, China

e-mail: zyma@imr.ac.cn the MMCs, shape memory alloys (SMAs), which could provide the MMCs with not only mechanical but also functional properties.

SMAs belong to a class of shape memory materials, which have the ability to 'memorize' or retain their previous form when subjected to certain stimulus such as thermomechanical or magnetic variations. Owing to their unique and superior properties, SMAs have drawn significant attention and interest in recent years in a broad range of applications [4, 5]. Most SMAs such as NiTi inherently exhibit a thermally or stress-driven phase transformation which comes from a reversible thermoelastic phase transformation between a low-temperature martensite phase (B19' or R structure) and a high-temperature austenite phase (B2 structure) [6-8], and this special ability provides them with three main interesting properties $[9,10]$ : (1) the potential to change from high to low damping characteristics through temperature or stress change; (2) a superelastic behavior in the austenitic state; and (3) the shape memory effect (SME) upon heating from a deformed martensitic state, with a possible two-way SME upon training. 
Therefore, SMAs can be considered as smart materials with marked variations in physical or mechanical properties, since they can sense thermal or stress stimulus and exhibit actuation or some pre-determined response, making it possible to control some technical parameters such as shape, strain, stiffness, natural frequency, damping and so on [10]. Moreover, these special characteristics can be maintained in the composites, which is one of the advanced materials for the 21 st century [11, 12]. For example, the hybrid polymer composites with embedded SMAs show great promise as materials able to adapt the shape, thermal behavior, or vibrational properties during service [13]. Furthermore, hybridizing composites using SMA is one solution to improve their impact damage tolerance since SMA materials can absorb the energy of the impact through superelastic deformation or recovery stress, reducing the effects of the impact on the composite structure [14].

On the other hand, it is well established that compressive residual stress in the matrix, caused by higher thermal expansion coefficient (CTE) of the reinforcement than that of the matrix [15], is beneficial to tensile properties, particularly fracture toughness [16, 17]. However, in most MMC systems, the CTE of reinforcements is much smaller than that of metal matrices, resulting in tensile residual stress in the matrices at room temperature. Hence, if there is a special reinforcement that shrinks in the matrices at the temperature of operation or with increasing applied stress, compressive stress may be introduced into the matrices, thus contributing to the tensile properties of the MMC [17].

In view of this, SMAs are excellent candidate reinforcements for this purpose. By incorporating SMAs into aluminum alloys, fiber or particle, SMAs-reinforced aluminum matrix composites (SMAs/Al) with special functions can be produced [17]. When the SMAs/Al composites are fabricated at high temperature and then cooled down to room temperature, a residual thermal stress is introduced into the composites due to the mismatch of the CTE between the SMA reinforcement and the $\mathrm{Al}$ matrix. During the past decades, much research has been focused on this respect. In this review article, the current state of the understanding and development of MMCs with reinforcement of SMAs is addressed.

\section{Strengthing Mechanism of Shape Memory Effect}

Furuya et al. [18, 19] designed a AMC reinforced by NiTi fiber $\left(\mathrm{NiTi}_{\mathrm{f}} / 1100 \mathrm{Al}\right)$. The design concept for the SMA/ metal composites strengthened by SME can be illustrated in Fig. 1: (a) the composite is prepared and heated to shape memorizing temperature, (b) cooled to martensitic phase, (c) subjected to tensile prestrain $\varepsilon$, and (d) heated above the

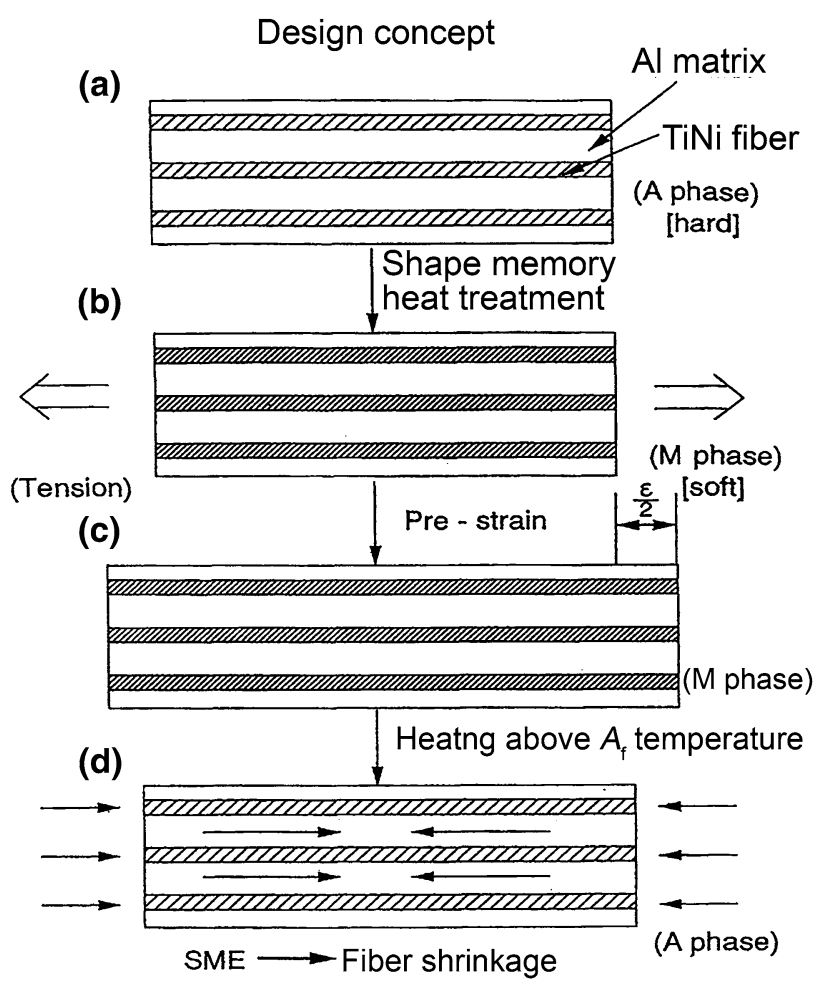

Fig. 1 Design concept of SMA fiber-reinforced aluminum matrix composite [18]

austenite finish temperature $\left(A_{\mathrm{f}}\right)$ when $\mathrm{TiNi}_{\mathrm{f}}$ shrinks to the length shape memorized at step (a). The last step induces the compressive stress in the matrix along the fiber axis while the fiber is in tension. Thus, when the composite is tested to obtain the tensile stress-strain curve, the unreinforced metal could be enhanced by two strengthening mechanisms: back stress strengthening and compressive stress strengthening induced by the shape memory effect.

It was considered that the induced compressive stress in the matrix is very useful for closing the micro-cracks in the composite because it can effectively decrease environmental stress, which in turn increases the fatigue life of the composite [19]. In consequence, the increases of the resistance to fatigue failure in the composite are attributed to three factors [19], as summarized schematically in Fig. 2: (a) large compressive stress effect by the shape memory shrinkages of SMA fibers plastically prestrained in the matrix, (b) higher stiffness value of the composite including the higher stiffness of austenite phase SMA, and (c) stress-induced phase transformation and the mechanical strain energy consumption (i.e., dispersion) which have successively occurred at the propagating fatigue crack-tip.

The SME strengthening mechanism of MMCs with dispersed SMA particles as schematically illustrated in Fig. 3 [20, 21]: (a) disperse the SMA particles uniformly in the matrix with the particles being perfectly bonded to the 

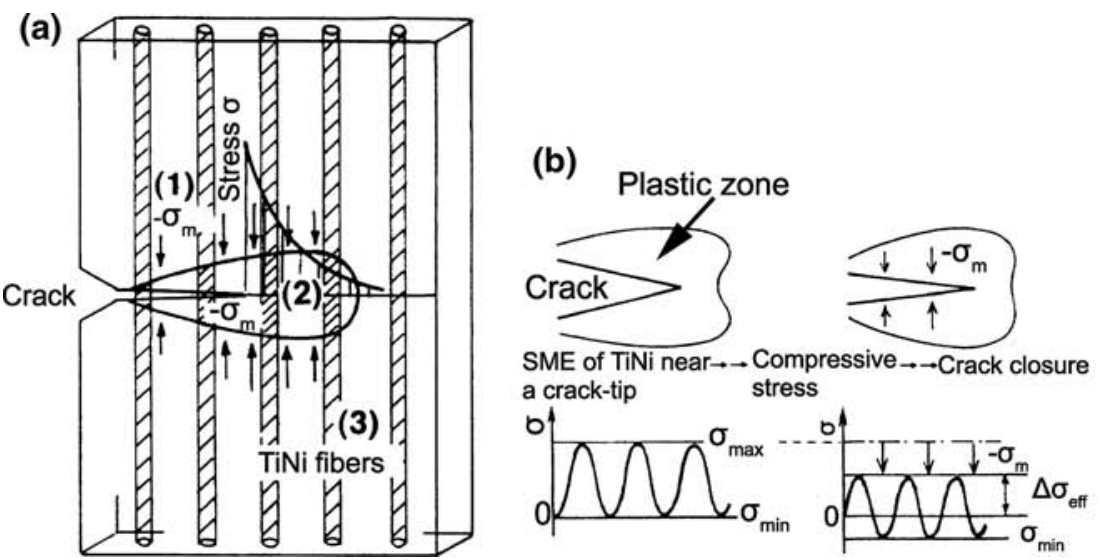

(c)
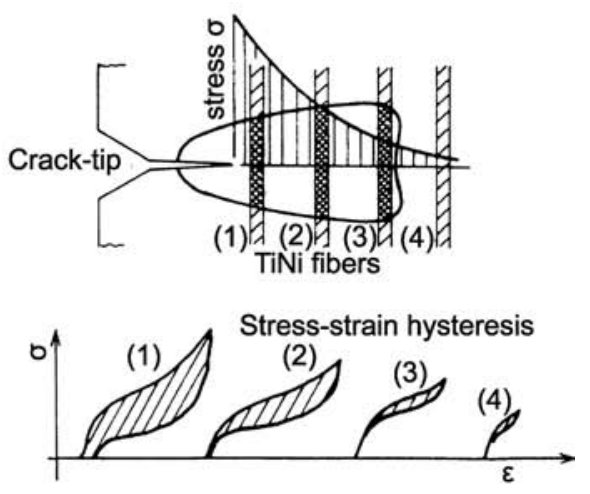

Fig. 2 Schematic figures concerning main factors for enhancing resistance to fatigue crack propagation: a compressive stress by shrinkages of $\mathrm{TiNi}$; $\mathbf{b}$ stress-induced phase transformation of TiNi at crack-tip, and $\mathbf{c}$ high stiffness of TiNi above $A_{\mathrm{f}}$ temperature [19]

(a)

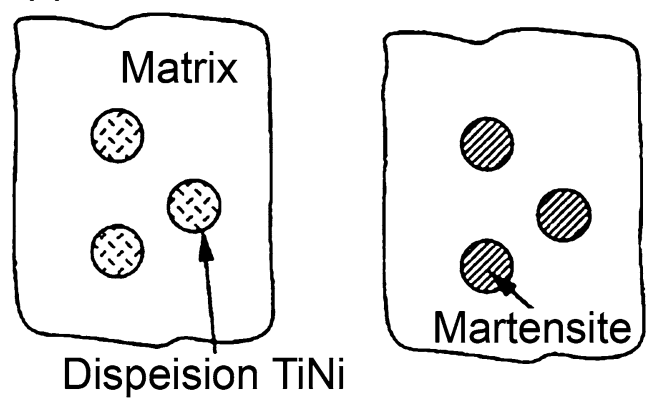

(c)

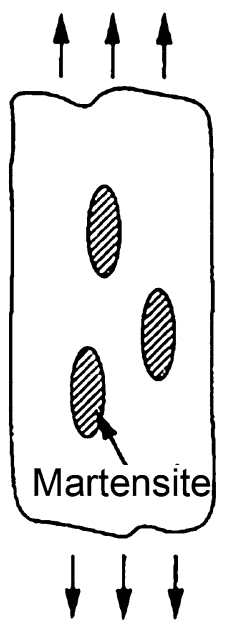

(d)

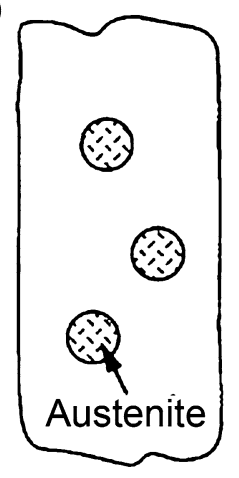

Fig. 3 Strengthening mechanism of composite by shape memory effect: a sintering; $\mathbf{b}$ shape memory heat treatment at $500{ }^{\circ} \mathrm{C}$, followed by icequenching; c deformation processing (below $A_{\mathrm{s}}$ ); d heat treatment above $A_{\mathrm{f}}[20]$

matrix (Fig. 3a); (b) conduct a shape memory treatment on the composite (Fig. 3b); (c) change the shape of SMA particles by giving prestrain to the composite at its martensitic stage (Fig. 3c); and (d) transform the SMA particles from martensite to austenite by heating the composite above the austenite starting point $\left(A_{\mathrm{s}}\right)$ (Fig. 3d). This shape recovery process induces compressive stress in the matrix along the prestrain direction, which in turn enhances the tensile properties of the composite at the austenitic stage. Meanwhile, this mechanism can also be applied to the long fiber and short fiber-reinforced composite.

\section{Fabrication of Long SMA Fiber/Wire-Reinforced AMCs}

SMA fibers are of particular interest for their high damping capacity and sensing and actuating functions. Accordingly, in the light of enhancing the tensile properties using compressive residual stress in the matrix of a composite, SMA fibers are excellent candidate fillers [11]. In fact, so far most efforts of producing SMA-reinforced MMCs are focused on the $\mathrm{NiTi}_{\mathrm{f}}$-reinforced AMCs, and the fabrication method mainly includes casting, vacuum hot pressing, and ultrasonic consolidation. AMCs reinforced with long SMA fiber/wire and their fabrication methods are summarized in Table 1.

\subsection{Casting}

It was reported that the AMC reinforced with SMA fibers (4-9 vol\% $\mathrm{NiTi}_{\mathrm{f}} / 1100 \mathrm{Al}$ ) was first prepared by pressure casting method $[18,19,22]$. The fibers were first arranged into a fixed holder which was perforated by a laser beam (fiber diameter $200 \mu \mathrm{m}$, hole diameter $300 \mu \mathrm{m}$ ), then the holder with the fibers was placed in a mold into which 
Table 1 Summary of the AMCs reinforced with long SMA fiber/wire and their fabrication methods

\begin{tabular}{|c|c|c|c|c|c|}
\hline Matrix & Reinforcement (vol\%) & Fabrication method & Temperature/pressure & Interface & Ref. \\
\hline $1100 \mathrm{Al}$ & $\operatorname{NiTi}_{\mathrm{f}}(4-9)$ & Pressure casting & $970 \mathrm{~K} / 65 \mathrm{MPa}$ & $4 \mu \mathrm{m}$ layer & {$[18,22]$} \\
\hline 1100Al & $\operatorname{NiTi}_{\mathrm{f}}(3)$ & Hot pressing & $843 \mathrm{~K} / 200 \mathrm{MPa}$ cool pressure & Unknown & [19] \\
\hline AC4AAl & $\mathrm{NiTi}_{\mathrm{w}}(2-4)$ & Squeeze casting & $1,023 \mathrm{~K} / 75 \mathrm{MPa}$ & $1.1 \mu \mathrm{m}$ layer & {$[23]$} \\
\hline $1060 \mathrm{Al}$ & $\operatorname{NiTi}_{\mathrm{f}}(20,30)$ & Pressure infiltration process & $973 \mathrm{~K} / 30 \mathrm{MPa}$ & Three layers $\mathrm{Al}_{3} \mathrm{Ti}, \mathrm{Al}_{3} \mathrm{Ni}$ & {$[24]$} \\
\hline 6061Al & $\mathrm{NiTi}_{\mathrm{f}}(19.5)$ & vacuum hot pressing & $813-823 \mathrm{~K} / 2,000 \mathrm{kgf}$ & Unknown & {$[26,27]$} \\
\hline $6082 \mathrm{Al}$ & $\operatorname{NiTi}_{\mathrm{f}}(\sim 20)$ & Hot pressing & $806-833 \mathrm{~K} / 25 \mathrm{MPa}$ & Unknown & [28-34] \\
\hline $6061 \mathrm{Al}$ & $\operatorname{NiTi}_{\mathrm{f}}(2.7-5.3)$ & Vacuum hot pressing & $813-823 \mathrm{~K} / 7-54 \mathrm{MPa}$ & $\mathrm{Al}_{3} \mathrm{Ti}, \mathrm{Al}_{3} \mathrm{Ni}$ & {$[35,36]$} \\
\hline $6061 \mathrm{Al}$ & $\mathrm{NiTi}_{\mathrm{f}}(3.2-7.0)$ & Hot-press method & 803-833 K/40-60 MPa & $400 \mu \mathrm{m}$ layer, $\mathrm{Ti}_{x} \mathrm{Al}_{y}$ & [37-39] \\
\hline \multicolumn{6}{|l|}{$2024 \mathrm{Al}$} \\
\hline Pure Al & $\operatorname{NiTi}_{\mathrm{f}}(6,20)$ & Vacuum hot pressed & $873 \mathrm{~K}$ & Unknown & {$[40-43]$} \\
\hline $\begin{array}{r}3003- \\
\text { H18 }\end{array}$ & $\mathrm{NiTi}_{\mathrm{f}} \mathrm{NiTi}$ ribbon $(5,15,20)$ & Ultrasonic consolidation & $<573 \mathrm{~K} /<300 \mathrm{kPa}$ & No & [44-48] \\
\hline $6061 \mathrm{Al}$ & NiTi (20) & Spark plasma sintering & $633-873 \mathrm{~K}$ & $\mathrm{Ni}_{3} \mathrm{Ti}, \mathrm{Ti}_{2} \mathrm{Ni}, \mathrm{Al}_{3} \mathrm{Ni}$ & [49] \\
\hline
\end{tabular}

molten aluminum is poured, followed by pressurization. It was reported that a thin diffusion region about $4 \mu \mathrm{m}$ in thickness was found across the fiber-matrix interface, and most of the $\mathrm{NiTi}_{\mathrm{f}}$ was not affected and reaction products such as $\mathrm{Ti}_{\mathrm{x}} \mathrm{Al}_{\mathrm{y}}$ were scarcely observed. Squeeze casting was also adopted to fabricate SMA/Al composite (2-4 vol\% NiTi wire/AC4A alloy) [23]: a preform was acid cleaned to remove the oxidation film on the TiNi wire, the conditions of squeeze casting were set as $673 \mathrm{~K}$ of mold preheating temperature, and $1,023 \mathrm{~K}$ of pouring temperature of molten $\mathrm{Al}$. It was reported that $\mathrm{Al}$ diffused to the TiNi wires with a thickness of $\sim 1.1 \mathrm{~m}$ and the composite showed fairly good pull-out strength, and the interfacial bond strength of the TiNi/A1 did not change much according to the conditions of the pouring temperature and mold preheating temperature.

Recently, Hu et al. [24, 25] fabricated a NiTi $/ 1060 \mathrm{Al}$ composite with $\mathrm{NiTi}_{\mathrm{f}}$ volume fractions of 20 and $30 \%$ by a pressure infiltration method. Different from the normal casting method, a pre-oxidation treatment was performed on the $\mathrm{TiNi}_{\mathrm{f}}$ at $873 \mathrm{~K}$ in air for $1-8 \mathrm{~h}$ with the aim to prevent serious interfacial reaction between the Al matrix and $\mathrm{TiNi}_{\mathrm{f}}$. When the temperature reached $973 \mathrm{~K}$, the molten 1060Al was poured into the mold in which the $\mathrm{TiNi}_{\mathrm{f}}$ were placed, followed by pressurization at $30 \mathrm{MPa}$.

Figure 4 shows the microstructure of the composite with various fiber oxidized durations. A dense oxide layer with main component of $\mathrm{TiO}_{2}$ phase was formed on the $\mathrm{TiNi}_{\mathrm{f}}$ surface after oxidized in air. With increase in oxidation time, the thickness of the interfacial layers between $\mathrm{TiNi}_{\mathrm{f}}$ and Al matrix increased, leading to decreased tensile strength and elongation of the composite. When the oxidation time was $1 \mathrm{~h}$, the tensile strength of the composite was very close to the theoretical value. At this time, the interfacial layer can be divided into three parts, as shown in
Fig. 5: Ti-O layer next to the Al matrix, thin middle layer containing $\mathrm{Ti}$ element, and the $\mathrm{Ti}-\mathrm{Ni}$ layer next to the $\mathrm{TiNi}_{\mathrm{f}}$. A similar multilayer was also formed in the interface when the TiNi fibers were oxidized for $2 \mathrm{~h}$ and $4 \mathrm{~h}$. However, some voids were found between "Ti-O" layer close to the Al matrix and "Ti-Ni" layer close to the TiNi fiber (Fig. 6). These voids would reduce the mechanical properties of the composite.

\subsection{Vacuum Hot Pressing}

It was reported that a composite of 19.5 vol\% $\mathrm{NiTi}_{\mathrm{f}} /$ 6061Al could be successfully fabricated by vacuum hot pressing [26, 27]. First, the fiber-laced sheets with an average lateral fiber spacing of $0.43 \mathrm{~mm}$ were stacked to the pressing direction. Then, the fiber-laced sheets were loaded into a BN powder-coated steel hot-pressing die, and high temperature vacuum consolidated. However, the interface reaction of the composite was not discussed. The fabrication of a similar $\mathrm{NiTi}_{\mathrm{f}} / 6082 \mathrm{Al}$ composite (Fig. 7) by vacuum hot pressing was also reported [28-34]. This processing method resulted in good macro-scale homogeneity and little internal porosity. However, a number of fiber clusters were present and a significant amount of side by side fiber contact occurred within the transverse planes (Fig. 8) [29, 32].

In order to keep the fibers aligned and to prevent them from contacting each other [26], a modified vacuum hotpressing method was developed to prepare $\mathrm{NiTi}_{\mathrm{f}} / 6061 \mathrm{Al}$ composite [35, 36]. First, the $\mathrm{TiNi}_{\mathrm{f}}$ were wound around 6061Al sheets at a constant spacing, and then the prepreg sheets were stuck between the press dies, as shown in Fig. 9. The effect of temperature and press pressure on bonding conditions between the fiber and the Al matrix was carefully investigated (Fig. 10). As the surface of Al sheets 
can be oxidized easily in air, a large plastic flow due to high pressure is required for breaking the oxidized surface layer, and an optimized fabrication condition is hot pressing performed at $773 \mathrm{~K}$ for $30 \mathrm{~min}$ at $54 \mathrm{MPa}$. As shown in Fig. 11, interfacial reactions between $\mathrm{NiTi}_{\mathrm{f}}$ and $\mathrm{Al}$ matrix were observed at high temperatures. It is considered that these brittle layers would be fractured easily during the tensile test, promoting interfacial sliding between the fiber and the matrix. This insufficient stress transfer from the fiber to the matrix with the interfacial sliding is expected to reduce the matrix residual stress, hence reducing the yield stress of the composite at higher temperatures [35]. The effect of temperature and press pressure on the interfacial bonding conditions was further investigated and optimized [37-39]. Interfacial reaction occurred between the $\mathrm{TiNi}_{\mathrm{f}}$ and Al matrix with two generated intermetallic layers, and the thickness of the diffusion layer is about $400 \mu \mathrm{m}$ with the component of $\mathrm{Ti}_{x} \mathrm{Al}_{y}$ existed.

The hot pressing method was also adopted to prepare pure Al composite with embedded $\mathrm{NiTi}_{\mathrm{f}}$ [40-43]. After cold-rolled $4 \%$ along the longitudinal direction of the $\mathrm{TiNi}_{\mathrm{f}}$ at room temperature to get the ability of SME, no pores or microcracks were observed at the interface of TiNif and Al matrix, but the interfacial reaction condition was not discussed.

\subsection{Ultrasonic Consolidation}

Considering that those processes such as casting and hot pressing are likely to damage or distort the ductile SMA fibers due to the applications of high temperature and high pressure, an ultrasonic consolidation technique was adopted to fabricate $\mathrm{AMC}\left(\mathrm{NiTi}_{\mathrm{f}} / 3003 \mathrm{Al}\right)$ with the aim of minimizing fiber damage/distortion and interfacial reaction $[44,45]$. The schematic diagram of the ultrasonic consolidation process is shown in Fig. 12. Al foils with a thickness of $100 \mu \mathrm{m}$ were used. Each monolithic tape was prepared by first welding two layers of the $\mathrm{Al}$ foils together, and then $\mathrm{NiTi}_{\mathrm{f}}$ were sandwiched between the two layers of the tapes and consolidated in the direction along the fiber length. Full consolidation was achieved within seconds at relatively low contact pressures $(<300 \mathrm{kPa})$ and at low temperatures ( $<25 \%$ of fusion temperature). It was reported that complete plastic flow was induced in the $\mathrm{Al}$ matrix (Fig. 13), which not only bonded the upper and lower matrix tapes, but also produced intimate contact with the $\mathrm{NiTi}_{\mathrm{f}}$. Neither visible voids/porosity nor chemical reaction was observed at the $\mathrm{NiTi}_{\mathrm{f}}-\mathrm{Al}$ interface.

Recently, an emerging rapid prototyping process based on ultrasonic metal welding, ultrasonic additive manufacturing (UAM), is adopted to fabricate Al composite with SMA reinforcement [46-48]. The primary benefit of UAM over other metal-matrix fabrication processes is the low process temperatures, as low as $25^{\circ} \mathrm{C}$. The schematic diagram of
UAM and the microstructure of $3003 \mathrm{Al}$ composite with embedded NiTi ribbon are shown in Fig. 14. First, the composite was fabricated by consolidating two $150 \mu \mathrm{m}$-thick 3003Al-H18 strips onto an Al baseplate. Next, a rectangular NiTi ribbon $254 \mu \mathrm{m}$ thick was placed on the surface and two additional $\mathrm{Al}$ tapes were welded. The interface between $\mathrm{NiTi}$ and $\mathrm{Al}$ seemed clean without intermetallics due to the extremely low processing temperature.

Besides the above-mentioned fabrication methods, spark plasma sintering (SPS) process was also used to produce SMA/AMC $\left(\mathrm{NiTi}_{\mathrm{f}} / 6061 \mathrm{Al}\right)$ [49]. The $\mathrm{Al}$ alloy powder with the $\mathrm{TiNi}_{\mathrm{f}}$ was readily consolidated into composite at temperatures between 633 and $873 \mathrm{~K}$. The relative packing density of the composite increased with increasing sintering temperature. Interfacial reaction occurred at the interfaces between the $\mathrm{Al}$ matrix and $\mathrm{TiNi}_{\mathrm{f}}$ and the reaction region was considered to consist of three intermetallic phases which are considered to be $\mathrm{Ni}_{3} \mathrm{Ti}$, $\mathrm{Ti}_{2} \mathrm{Ni}$, and $\mathrm{Al}_{3} \mathrm{Ni}$. The thickness of the interfacial reaction region was almost constant regardless sintering temperature, and it is large when $\mathrm{TiNi}_{\mathrm{f}}$ is small in diameter.

\section{Fabrication of Short SMA fiber-Reinforced AMCs}

The unidirectional orientation of continuous fibers may restrict the application of the composites to simple loading conditions. In order to manufacture complex parts, the design concept of short NiTi fiber-reinforced AMC was proposed (Table 2).

So far, most AMC reinforced by short SAM fiber are NiTif/6061Al produced by pressure-assisted sintering in ambient air [50-53] or under vacuum [54], and the short $\mathrm{NiTi}_{\mathrm{f}}$ volume fraction is 5\% [50-52], 0.4\% [53], and 3\% [54], respectively. Xie et al. [50] fabricated a 6061 Al matrix composite reinforced by short $\mathrm{NiTi}_{\mathrm{f}}$. The short fibers were produced by chopping a NiTi ribbon into small pieces, with an aspect ratio of about 15 . The short $\mathrm{NiTi}_{\mathrm{f}}$ were mixed with $6061 \mathrm{Al}$ powder and pressure-assisted sintering in ambient air. Meanwhile, the AMC hybrid reinforced by short $\mathrm{NiTi}_{\mathrm{f}}$ and $\mathrm{SiCp}$ can also produced by this method [51]. It was reported that extensive diffusion from both $\mathrm{NiTi}_{\mathrm{f}}$ and $\mathrm{Al}$ alloy matrix occurred during the fabrication, and interfaicl reaction was found in this kind of composite [52]: $\mathrm{Al}_{3} \mathrm{Ti}$ with $\mathrm{DO}_{22}$ ordered structure near the NiTi side, $\mathrm{Al}_{9} \mathrm{FeNi}$ with $\mathrm{Al}_{9} \mathrm{Co}_{2}$ (or $\mathrm{Al}_{9} \mathrm{Fe}_{2}$ ) type ordered structure near the $\mathrm{Al}$ side (Fig. 15), and $\mathrm{Mg}-\mathrm{O}$ layer $20 \mathrm{~nm}$ in thickness between $\mathrm{Al}_{3} \mathrm{Ti}$ and $\mathrm{Al}_{9} \mathrm{FeNi}$ layers (Fig. 16). The minor elements in the matrix could be the major elements at the interface. As a result, it is suggested that it is possible to control the chemical composition at the interface and further control the mechanical properties of the composites by selecting the chemical composition of the $\mathrm{Al}$ alloy matrix. 

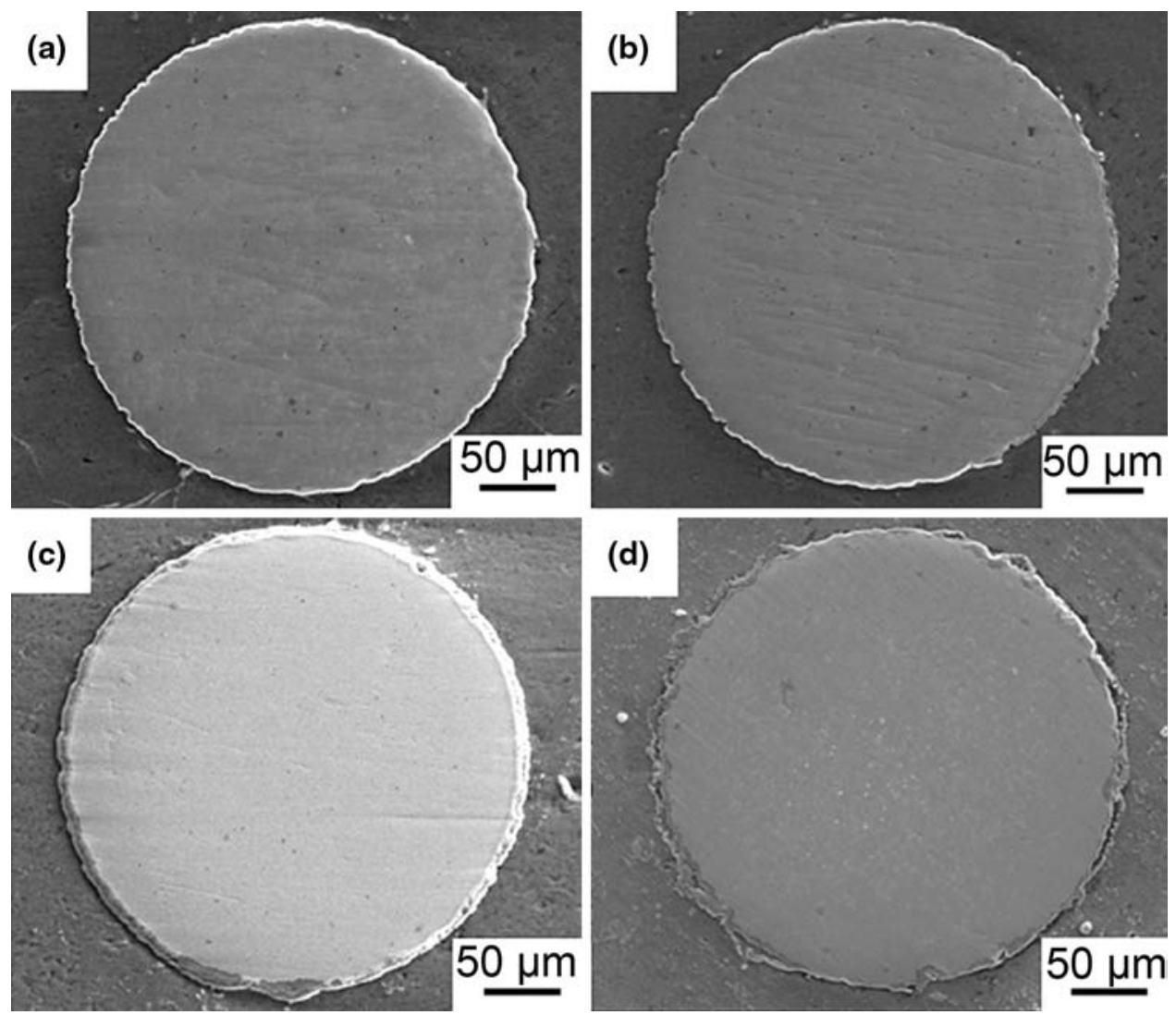

Fig. 4 Microstructure of $\mathrm{TiNi}_{\mathrm{f}} / \mathrm{Al}$ composite when $\mathrm{TiNi}_{\mathrm{f}}$ was oxidized for different time durations: a $1 \mathrm{~h}$; b $2 \mathrm{~h}$; c $4 \mathrm{~h}$; d 8 h [24]
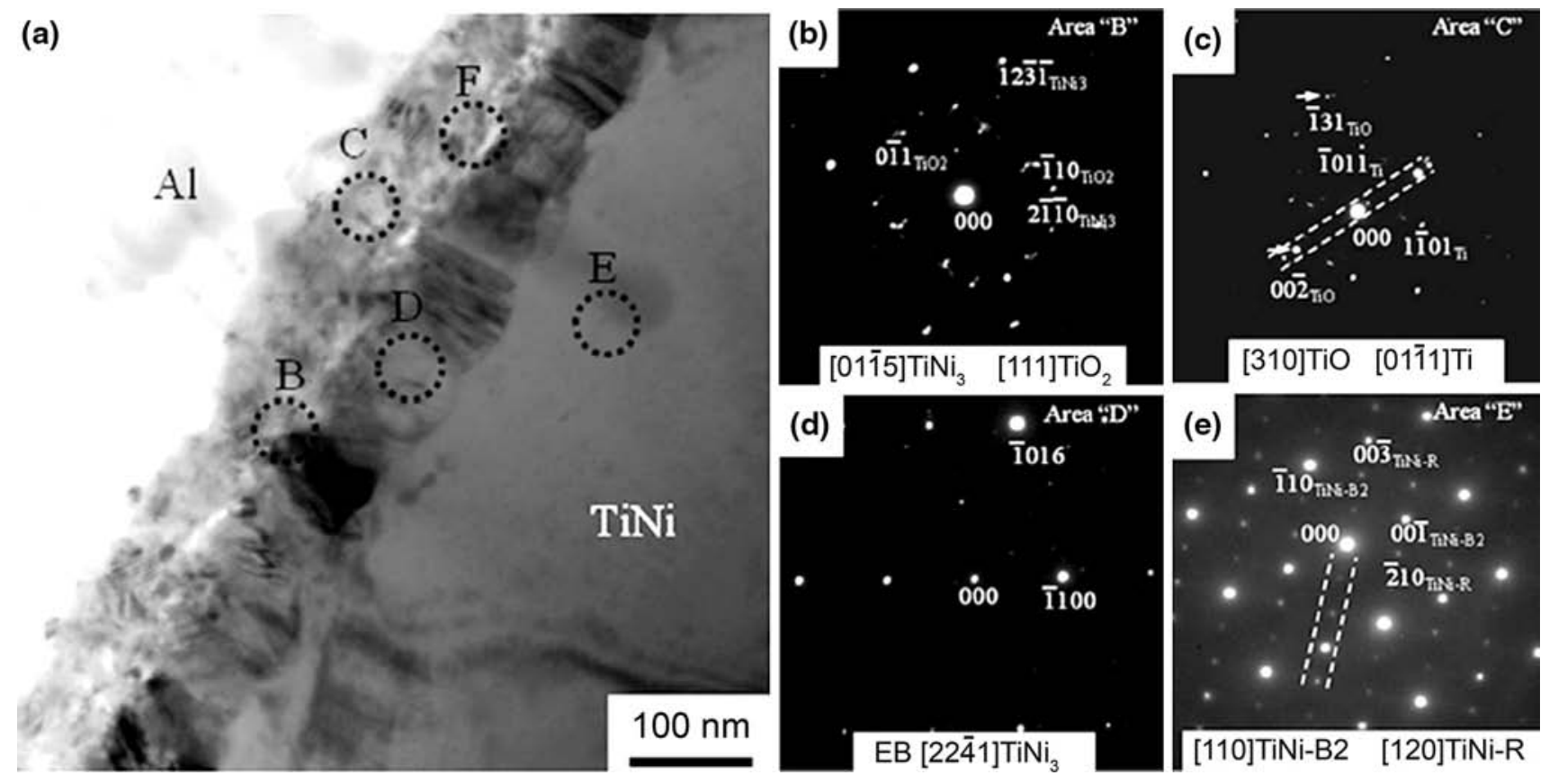

Fig. 5 a Bright-field TEM image of $\mathrm{NiTi}_{\mathrm{f}} / \mathrm{Al}$ interface with $\mathrm{TiNi}_{\mathrm{f}}$ pre-oxidized for $1 \mathrm{~h} ; \mathbf{b}$, c electron diffraction patterns of areas $\mathrm{B}$ to $\mathrm{E}$ in $\mathbf{a}$ close to $\mathrm{Al}$ and $\mathrm{NiTi}_{\mathrm{f}}$, respectively [24] 


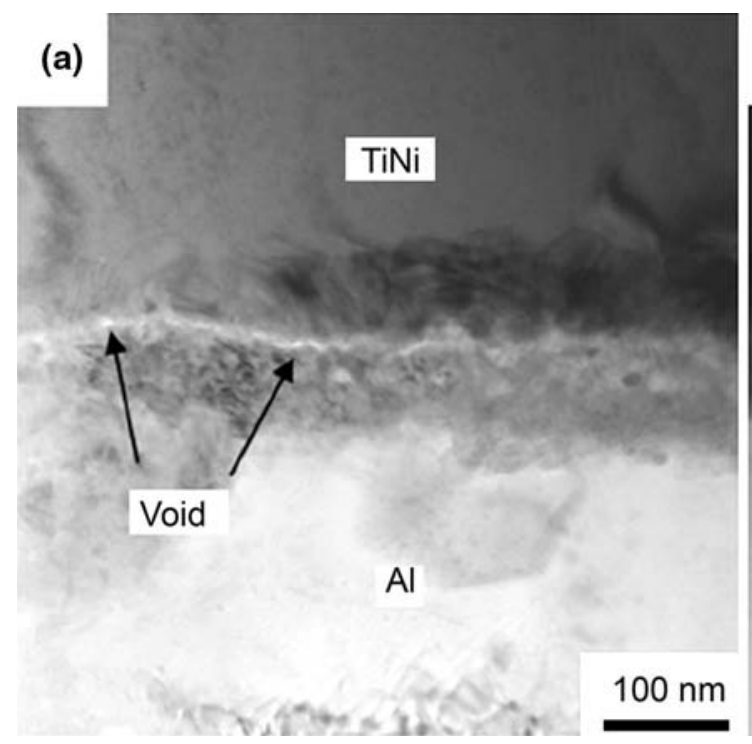

(b)

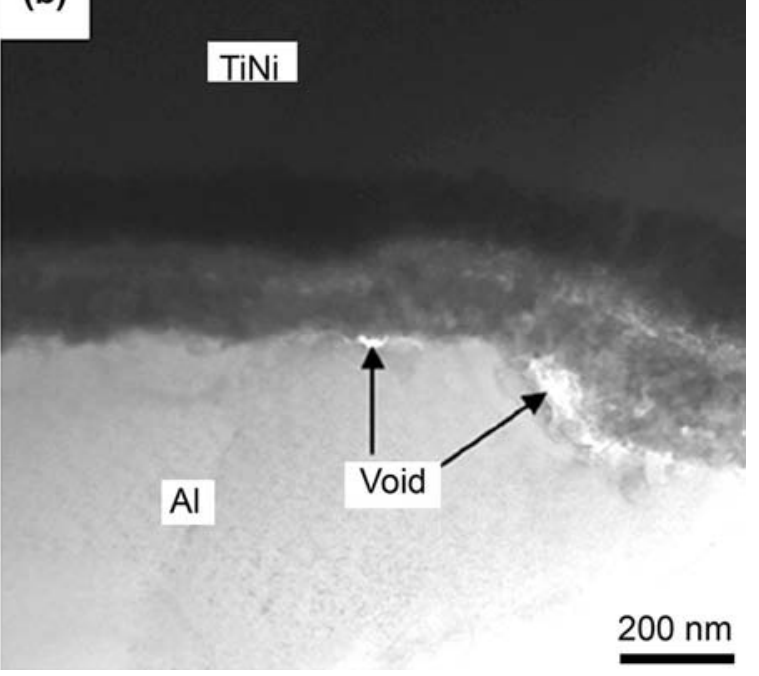

Fig. 6 TEM images of $\mathrm{NiTi}_{\mathrm{f}} / \mathrm{Al}$ interface with $\mathrm{TiNi}_{\mathrm{f}}$ pre-oxidized for $2 \mathrm{~h}$ a, $4 \mathrm{~h} \mathbf{b}$ [24]

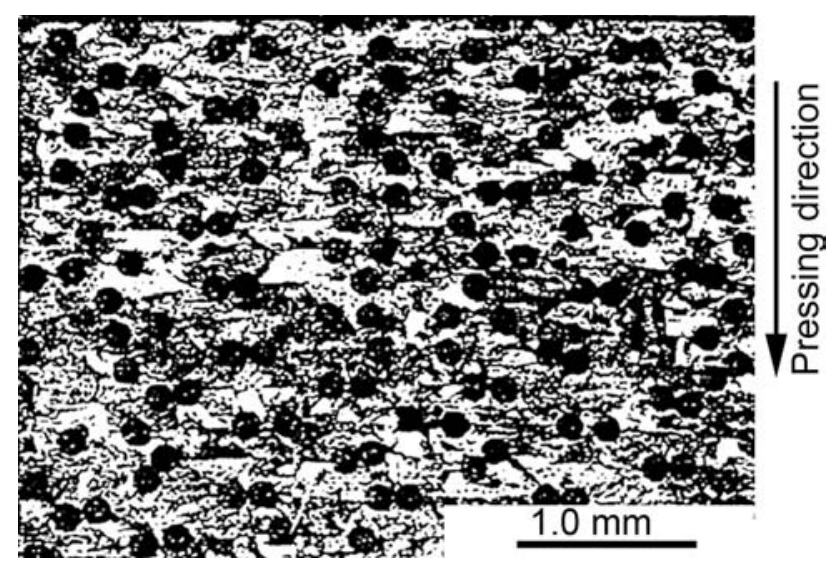

Fig. 7 Composite lateral section microstructure of $\mathrm{NiTi}_{\mathrm{f}} / 6082 \mathrm{Al}$ composite fabricated by vacuum hot pressing [28]

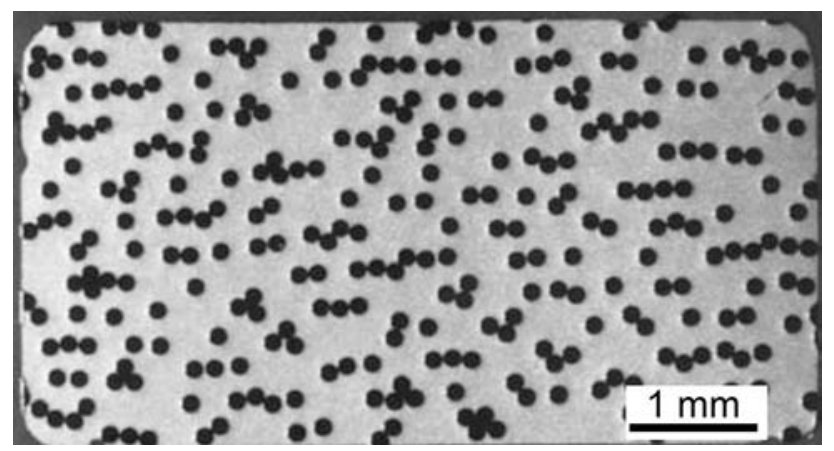

Fig. 8 Optical image of cross section of $\mathrm{NiTi}_{\mathrm{f}} / 6082 \mathrm{Al}$ composite prepared by vacuum hot pressing [29]

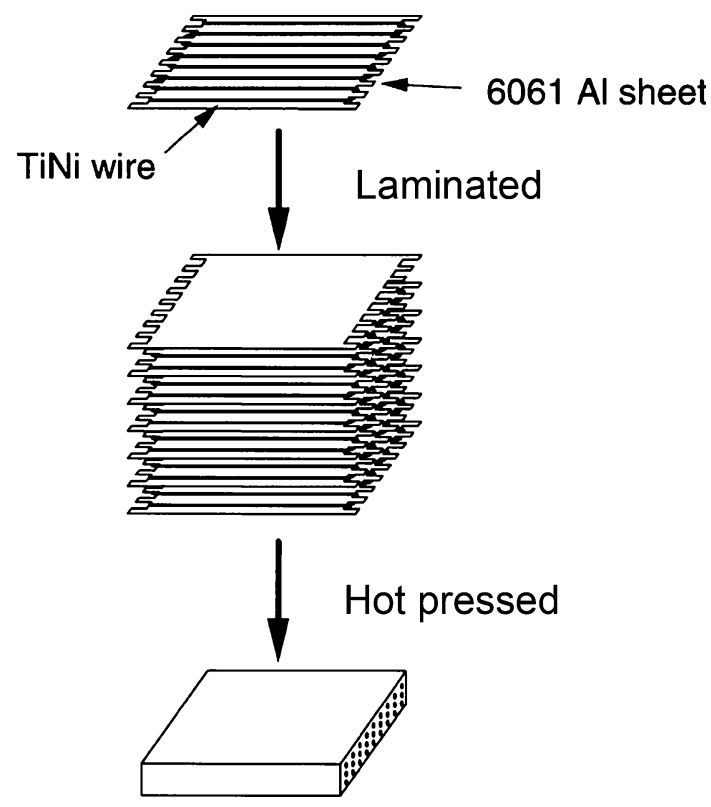

Fig. 9 Prepreg setting for a vacuum hot pressing of $\mathrm{NiTi}_{\mathrm{f}} / \mathrm{Al}$ composite [35]

Meanwhile, the $\mathrm{NiTi}_{\mathrm{f}}$ diameters $(127$ and $51 \mu \mathrm{m})$ could also affect the interface bonding condition [53], the NiTi fibers with smaller diameter $(51 \mu \mathrm{m})$ could better bonded with the Al matrix, and interfacial debonding was seldom observed. It is suggested that there is better microstructural compatibility, i.e., fiber diameter is of the same order as the Al matrix grain size for this case. However, for the large $\mathrm{NiTi}_{\mathrm{f}}(127 \mu \mathrm{m})$, debonding and "pull-out' phenomena could be frequently observed. Investigation on an $\mathrm{Al}-\mathrm{Si}$ alloy reinforced by short $\mathrm{NiTi}_{\mathrm{f}}$ [54] showed that the 

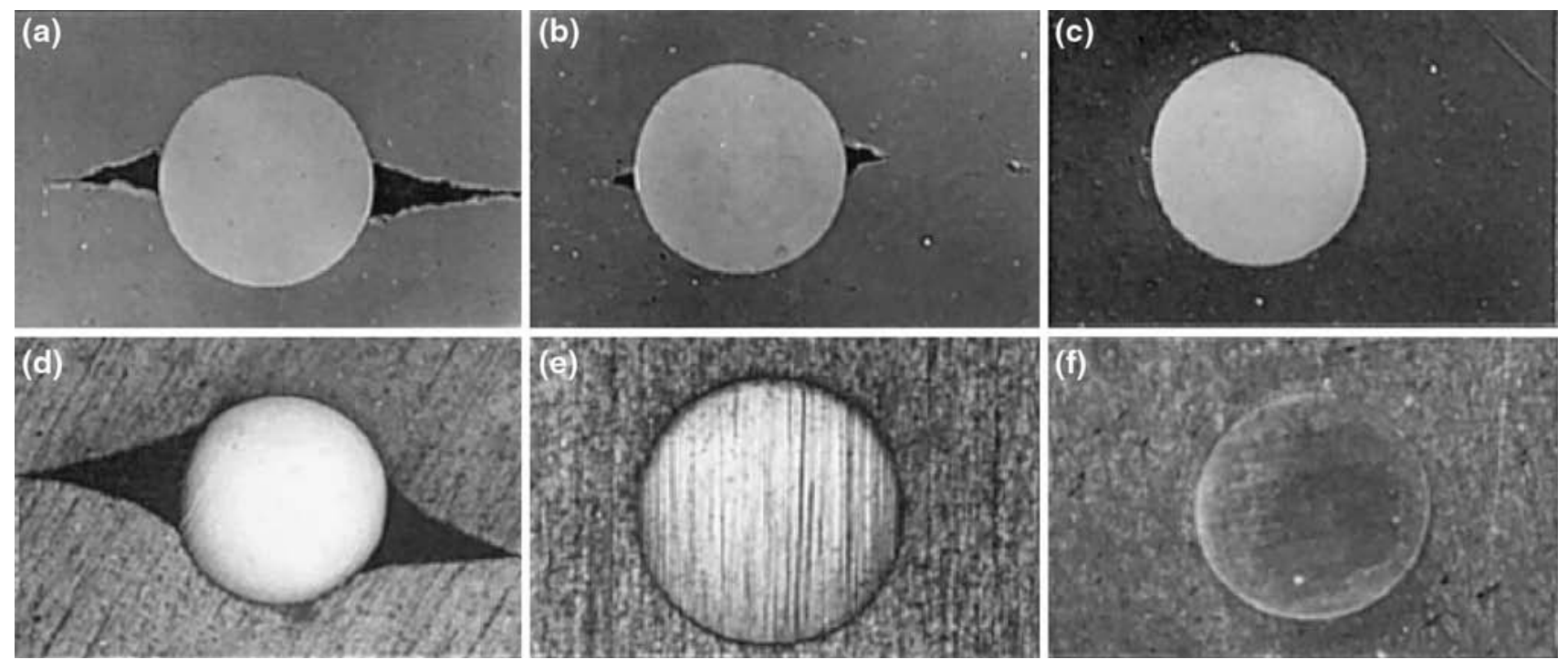

Fig. 10 Effects of temperature and press pressure on bonding conditions between $\mathrm{NiTi}_{\mathrm{f}}$ and $\mathrm{Al}$ sheets in $\mathrm{TiNi}_{\mathrm{f}} / 6061 \mathrm{Al}$ composite $($ the fiber diameter is $200 \mu \mathrm{m}$ ): a $773 \mathrm{~K}, 7 \mathrm{MPa}$; b $823 \mathrm{~K}, 7 \mathrm{MPa}$; c $873 \mathrm{~K}, 7 \mathrm{MPa}$; d $773 \mathrm{~K}, 14 \mathrm{MPa}$; e $823 \mathrm{~K}, 14 \mathrm{MPa}$; f $773 \mathrm{~K}, 54 \mathrm{MPa}$ [35]
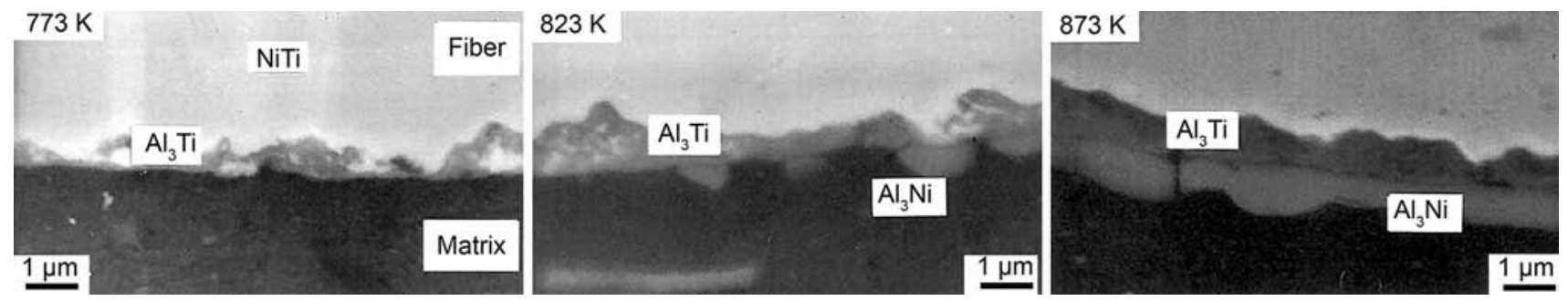

Fig. $11 \mathrm{SEM}$ images of interfacial microstructure of $\mathrm{TiNi}_{\mathrm{f}} / 6061 \mathrm{Al}$ composite with process temperatures of 773,823 and $873 \mathrm{~K}$ [35]

interface area increased and a double layer was formed with an outer and inner interfaces for longer sintering time, presenting different chemical compositions. This is explained by a longer diffusion time for fiber and matrix elements, allowing deeper reaction and a larger amount of interface compounds. Shear tests showed a decaying of shear strength with increasing sintering stage, with the lowest sintering time leading to higher properties.

\section{Fabrication of SMA Particle-Reinforced AMCs}

Particulate-reinforced AMCs have developed remarkably during the last 30 years as a result of their feasibility for low density, promising mechanical properties, mass production, and relatively low cost. AMCs reinforced with SMA particles and their fabrication methods are summarized in Table 3.

Powder metallurgy is effective to prepare the SMA particles reinforced $\mathrm{AMC}$, and $\mathrm{NiTi}_{\mathrm{p}}$ is the most popular reinforcement [21, 22]. Generally, $\mathrm{NiTi}_{\mathrm{p}}$ and $\mathrm{Al}$ powders were mixed and cool or hot compacted to a cylinder shape, and a following extrusion process is needed or not. $\mathrm{NiTiCu}$ particles reinforced AMCs were also investigated by first generating $\mathrm{NiTiCu}$ particles from mixed $\mathrm{Ti}, \mathrm{Ni}$, and $\mathrm{Cu}$ powders and then further mixed with Al powders [55], or by directly mixing $\mathrm{NiTiCu}$ particle and $\mathrm{Al}$ powders [56, 57]. It was revealed that the $\mathrm{TiNiCu}$ particles and the composite show reversible thermoelastic martensitic transformations as in the bulk material [56]. The preliminary results indicate that the composite may be a promising smart composite with native sensing, high damping capacity, and adaptive performances.

Porter et al. [58] prepared a $\mathrm{NiTi}_{\mathrm{p}} / \mathrm{Al}$ composite by mechanical milling and powder metallurgy. This process reduced the particle sizes thereby roughening the surface texture and enhancing the particle-to-matrix bonding interface. The powders were then subjected to a heat treatment to recover its SME but also deposited a thin oxide layer on the surfaces of the $\mathrm{NiTi}_{\mathrm{p}}$, which allowed the SME to be preserved in the material and inhibited the elemental diffusion through the hot pressing. The SME remained after the reduction of the NiTi size, but it was not as pronounced as that of the as-received condition. Meanwhile, quite a bit of diffusion between the NiTi 


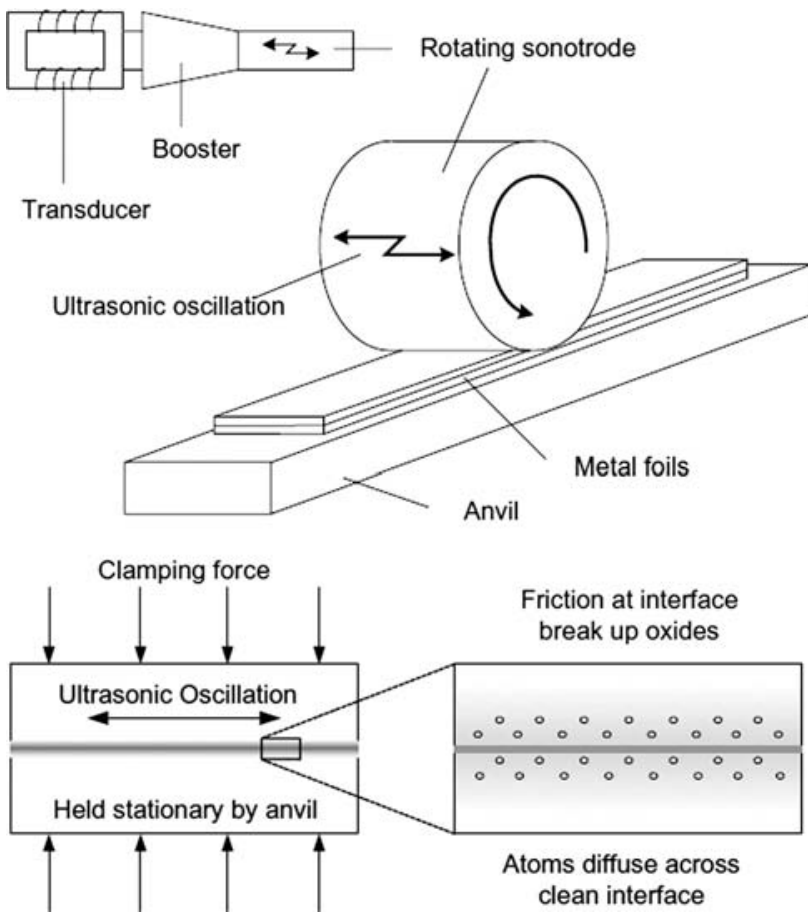

Fig. 12 Schematic diagram of ultrasonic consolidation process [44]

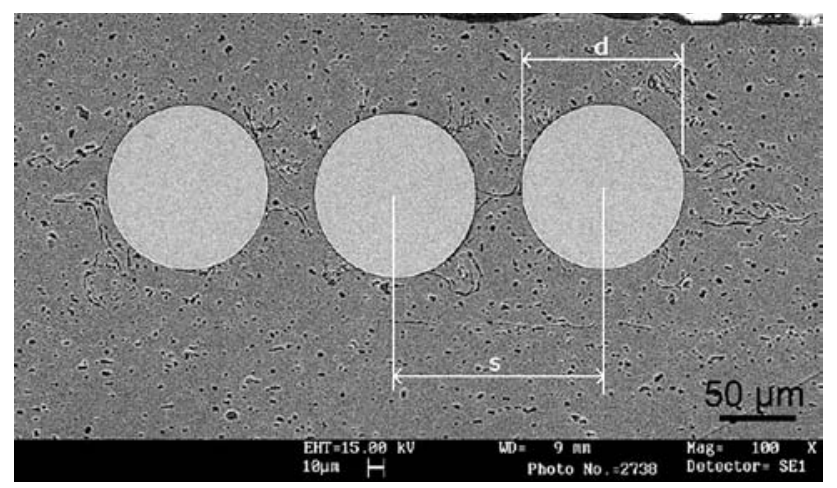

Fig. 13 SEM micrograph of SMA-embedded specimen prepared by ultrasonic consolidation process [44]

particles and $\mathrm{Al}$ matrix was evident, which led to the formation of intermetallics.

For the powder metallurgy process of a $\mathrm{NiTi}_{\mathrm{p}} / 2124 \mathrm{Al}$ composite, at a relatively low sinter temperature but long time $(773 \mathrm{~K} / 90 \mathrm{~min}$ and then hot extruded at $753 \mathrm{~K})$, the interface reaction between the $\mathrm{NiTi}_{\mathrm{p}}$ and $\mathrm{Al}$ was still obvious [59]: $\mathrm{NiTi}_{\mathrm{p}}$ were surrounded by a layer of interface products, $\mathrm{Al}_{3} \mathrm{Ti}$ and $\mathrm{Al}_{3} \mathrm{Ni}$; meanwhile, $\mathrm{Al}$ atoms diffused into the $\mathrm{NiTi}_{\mathrm{p}}$ to form an Al-rich layer (Fig. 17). The presence of $\mathrm{Al}$ lowered the $\mathrm{Ni}$ concentration of $\mathrm{NiTi}_{\mathrm{p}}$, and this affected the transformation behavior by broadening the intermediate R-phase transformation range [59]. After shortening the sintering time from 90 to $15 \mathrm{~min}$ and
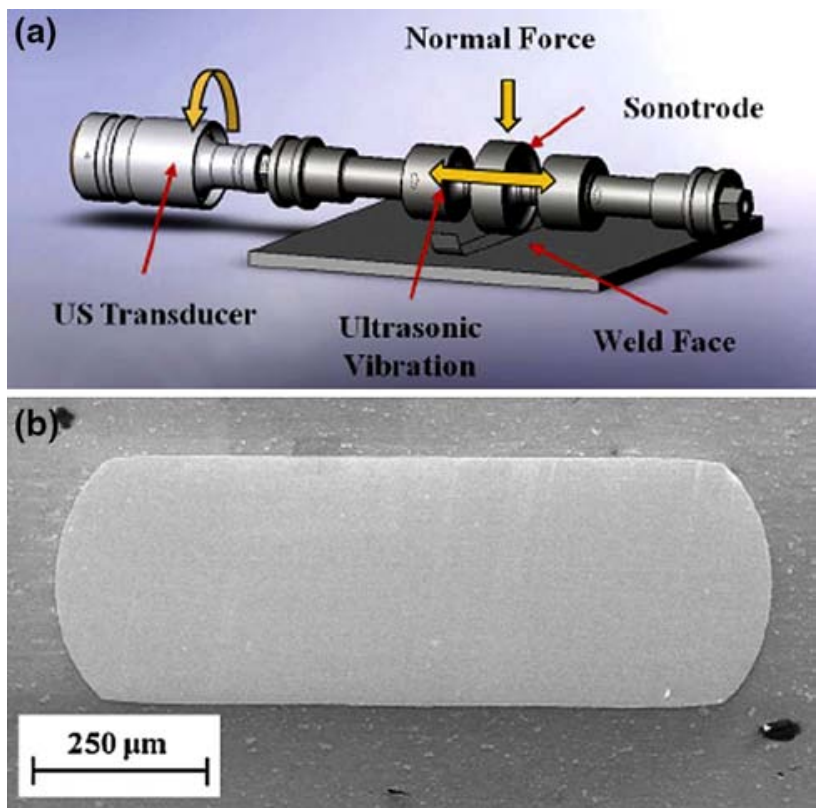

Fig. 14 a In UAM process, successive layers of metal tape are bonded together to create metallic composites with embedded materials. b Cross section of Al composite with embedded NiTi ribbon. [48]

decreasing the extrusion temperature from 753 to 703-713 K, no intermetallics were observed at the interface (Fig. 18) [60]. However, for the powder metallurgy process, the considerably shortened sintering time and lower temperature are not beneficial to the diffusion and bonding between the powders, and the densification of the billets, especially for the preparation of large billets. For a porous TiNi alloy prepared by self-propagating high-temperature synthesis (SHS) [61], severe interfacial reaction took place during the following infiltration process of liquid Al: NiAlTi intermetallics were formed at the phase boundary between $\mathrm{TiNi}$ and $\mathrm{Al}$ phases, and $\mathrm{Ni}_{3}(\mathrm{AlTi}$ ) and $\mathrm{AlNi}_{2} \mathrm{Ti}$ phases were formed in the $\mathrm{Al}$ matrix.

Recently, $\mathrm{NiTi}_{\mathrm{p}} / \mathrm{Al}$ composite prepared by friction stir processing (FSP) was reported [62, 63]. FSP is a novel multi-functional processing method based on friction stir welding [64, 65] and was normally adopted to prepare ceramic particles reinforced MMC [66, 67]. Dixit et al. [62] first reported the fabrication of a $\mathrm{NiTi}_{\mathrm{p}} / 1100 \mathrm{Al}$ surface composite ( $2 \mathrm{~mm}$ in thickness) by FSP. In their study, the $\mathrm{NiTi}_{\mathrm{p}}$ were preseted into four holes, $1.6 \mathrm{~mm}$ in diameter and $76 \mathrm{~mm}$ in length, drilled at about $0.9 \mathrm{~mm}$ below the plate surface and parallel to the surface. Then, the processed plate was subjected to FSP and a surface composite was obtained. $\mathrm{NiTi}_{\mathrm{p}}$ were homogeneously distributed in the $\mathrm{Al}$ matrix and no interfacial reaction occurred around the $\mathrm{NiTi}_{\mathrm{p}}$ (Fig. 19). They reported that the SME of the $\mathrm{NiTi}_{\mathrm{p}}$ could induce residual compressive and tensile stresses in 
Table 2 Summary of AMCs reinforced with short SMA fiber and their fabrication methods

\begin{tabular}{|c|c|c|c|c|c|}
\hline Matrix & $\begin{array}{l}\text { Reinforcement } \\
\text { (vol\%) }\end{array}$ & Fabrication method & Temperature/pressure & Interface & Ref. \\
\hline $6061 \mathrm{Al}$ & $\mathrm{NiTi}_{\mathrm{f}}(5)$ & Pressure-assisted sintering in ambient air & $\begin{array}{l}843-853 \mathrm{~K} / \\
50-70 \mathrm{MPa}\end{array}$ & 3-layers, $\mathrm{Al}_{3} \mathrm{Ti}$, etc. & $\begin{array}{r}{[50-} \\
52]\end{array}$ \\
\hline $6061 \mathrm{Al}$ & $\mathrm{NiTi}_{\mathrm{f}}(0.4)$ & Pressure-assisted sintering in ambient air & $\begin{array}{l}658 \mathrm{~K} / 60-70 \mathrm{MPa} \\
858 \mathrm{~K}\end{array}$ & $\begin{array}{l}\mathrm{Al}-\mathrm{Ti}-\mathrm{Ni}, \mathrm{Al}-\mathrm{Fe}-\mathrm{Ni} \\
\text { compounds }\end{array}$ & {$[53]$} \\
\hline $\begin{array}{l}\mathrm{AlSi} \\
\text { alloy }\end{array}$ & $\operatorname{NiTi}_{\mathrm{f}}(3)$ & $\begin{array}{l}\text { Pressure-assisted sintering process under } \\
\text { vacuum }\end{array}$ & $823 \mathrm{~K} / 6.5 \mathrm{MPa}$ & $\begin{array}{l}\text { 2-layers, } \mathrm{Al}-\mathrm{Fe}-\mathrm{Ni} \\
\text { compound }\end{array}$ & {$[54]$} \\
\hline
\end{tabular}

the matrix, improving the mechanical properties of the composite. This indicates that the SMAs reinforced MMCs with a good interfacial bonding could be prepared by FSP. However, in order to achieve a wide application of the SMAs reinforced AMCs, it is necessary to fabricate the bulk composites to understand their physical and mechanical properties associated with the SME.

Recently, $\mathrm{Ni}$ et al. [63] prepared a bulk $\mathrm{NiTi}_{\mathrm{p}} / 6061 \mathrm{Al}$ composite by FSP. Figure 20 shows the schematic diagram of preparing the bulk NiTi $/ 6061 \mathrm{Al}$ composites by FSP. A series of holes were machined on the plates perpendicular to the plate surface. Four-pass FSP, with a $100 \%$ overlap and the same forward directions, was conducted to the $\mathrm{NiTi}_{\mathrm{p}}$-filled plates at a tool rotation rate of $600 \mathrm{r} / \mathrm{min}$ and a traversing speed of $100 \mathrm{~mm} / \mathrm{min}$. The $\mathrm{NiTi}_{\mathrm{p}} / 6061 \mathrm{Al}$ composite with a thickness of about $5 \mathrm{~mm}$ was prepared and much thicker than the surface composite $(\sim 2 \mathrm{~mm})$ in Ref. [62]. The volume fraction of the $\mathrm{NiTi}_{\mathrm{p}}$ in the composites was estimated to about $10 \%$. The microstructure analysis (Fig. 21) shows that $\mathrm{NiTi}_{\mathrm{p}}$ were homogeneously distributed in the $\mathrm{Al}$ matrix, and the interface between the $\mathrm{NiTi}_{\mathrm{p}}$ and the Al matrix was clean without discernible reaction products. After a T6 heat treatment (solution treated at $515{ }^{\circ} \mathrm{C}$ for $40 \mathrm{~min}$, water quenched, and aged at $163{ }^{\circ} \mathrm{C} / 18 \mathrm{~h}$ ), the interface was still clean and no reaction products were detected (Fig. 22). This means that the $\mathrm{NiTi}_{\mathrm{p}}$ were stable in the $\mathrm{Al}$ matrix at a high temperature up to $515^{\circ} \mathrm{C}$ after $40 \mathrm{~min}$, indicating that the as-FSP composite could be strengthened through the conventional T6-treatment.

As discussed above, it is clear that how to control the interfacial reaction between $\mathrm{NiTi}_{\mathrm{p}}$ and $\mathrm{Al}$ matrix is the most important challenge to produce the $\mathrm{NiTi}_{\mathrm{p}} / \mathrm{Al}$ composites. For the as-FSP composites, the interfacial reaction was completely inhibited due to the following two factors. First, the duration of the FSP process was significantly shorter than that of the casting and PM processes, the thermal exposure to higher temperatures lasted only about several seconds and the whole FSP process lasted only about several minutes [68]. Second and most important, the temperature during FSP was much lower than that during the casting and PM processes. For example, the maximum temperature in the nugget during FSW of $6063 \mathrm{Al}$ was about only $400{ }^{\circ} \mathrm{C}$ at a rotation rate of $800 \mathrm{r} / \mathrm{min}$ [68].

\section{Other MMC with Reinforcement of SMA}

Except the AMCs reinforced by SMA, other MMCs with reinforcement of SMA were also reported during the last two decades, such as $\mathrm{Mg}, \mathrm{Ti}$, and In alloys, as shown in Table 4.

Pulsed current hot pressing (PCHP) was used to fabricate a $\mathrm{NiTi}_{\mathrm{f}} / \mathrm{AZ31}$ composite (Fig. 23) [69, 70]. Mg alloy plates with $20 \mathrm{vol} \%$ of $\mathrm{TiNi}_{\mathrm{f}}$ were readily hot pressed into a composite at $773 \mathrm{~K}$. It seemed that interface reaction occurred in the vicinity of the boundary between $\mathrm{Mg}$ and $\mathrm{TiNi}_{\mathrm{f}}$, but no homogeneous interfacial reaction layer was formed (Fig. 24). The interfacial region between the fiber and the matrix consisted of two phases. About 2- $\mu \mathrm{m}$-thick layer containing $\mathrm{Al}$ and $\mathrm{Ni}$ elements was formed next to the matrix and about $10-\mu$ m-thick layer containing $\mathrm{Mg}, \mathrm{Al}, \mathrm{Ni}$, and $\mathrm{O}$ elements was formed next to the fiber. A ball-milling combined with hotpressing process was also adopted to prepare $\mathrm{NiTi}_{\mathrm{f}} / \mathrm{Mg}$ composite [71]. Ball-milled powders of $\mathrm{Mg}$ alloy with different contents of $\mathrm{NiTi}_{\mathrm{f}}$ were put into a monoaxial pressing die, in which the fibers in a row were sandwiched between two layers of the Mg powders. The mixed $\mathrm{Mg}$ powder and $\mathrm{NiTi}_{\mathrm{f}}$ were hot pressed at a relatively low temperature of $320{ }^{\circ} \mathrm{C}$ with an applied high pressure of $375 \mathrm{MPa}$ under which the $\mathrm{TiNi}_{\mathrm{f}}$ were not damaged or deformed. Microstructure analysis (Fig. 25) shows that a nearly full dense matrix was achieved, and remarkable interfacial reaction product or layer was not observed, indicating that the extremely low hot-pressing temperature is a key factor to control the interfacial between the NiTi and Mg matrix.

Recently, Li et al. [72] provided an innovative method combining pore-forming technique, powder sintering, and 


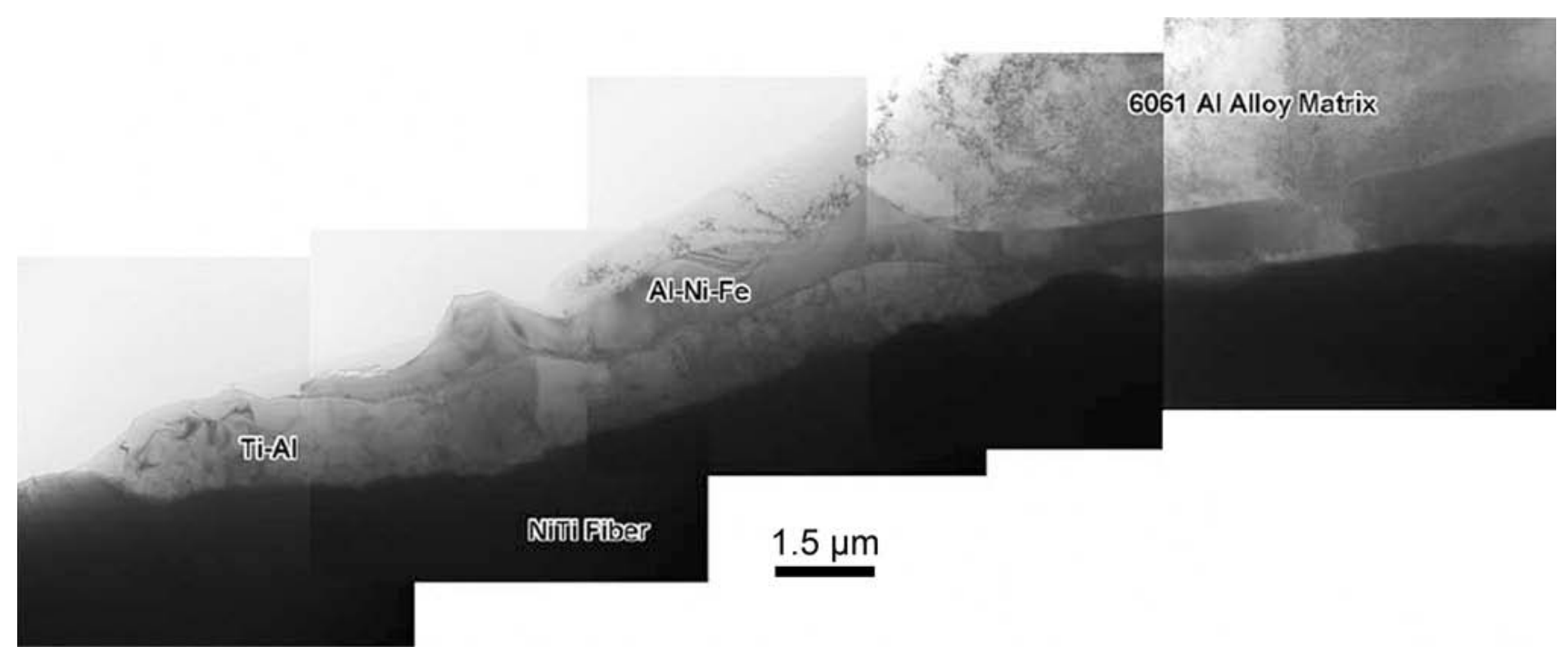

Fig. 15 TEM bright-field image showing multilayers formed at interface of NiTi/6061 Al composite [52]

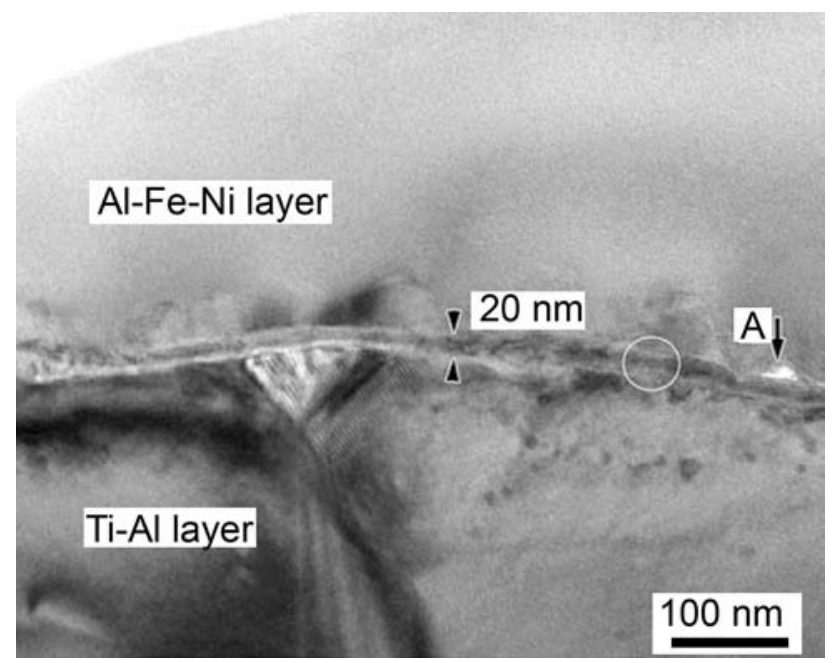

Fig. $16 \mathrm{Mg}-\mathrm{O}$ thin layer $20 \mathrm{~nm}$ in thickness between $\mathrm{Al}_{3} \mathrm{Ti}$ and $\mathrm{Al}_{9} \mathrm{FeNi}$ layers [52]

pressureless infiltration of liquid $\mathrm{Mg}$ alloy to fabricate NiTi shape memory alloy-based composites $(\mathrm{Mg} / \mathrm{NiTi})$. The results showed the existence of minor $\mathrm{Ni}_{x} \mathrm{Ti}_{y}$ phases such as $\mathrm{NiTi}_{2}$ and $\mathrm{Ni}_{3} \mathrm{Ti}$ in the NiTi matrix as well as non- $\mathrm{Ni}_{x} \mathrm{Ti}_{y}$ phases (e.g., $\mathrm{Mg}_{2} \mathrm{Ni}$ and $\mathrm{MgO}$ ) mainly in the infiltrating material owing to the inevitable reaction between $\mathrm{Mg}, \mathrm{NiTi}$ and residual oxygen (Fig. 26). They indicated that the Mg/ $\mathrm{NiTi}$ composites possessed excellent mechanical and physical properties, such as high damping capacity, high fracture strength, and low density. This study indicates that if a Mg matrix composite with NiTi reinforcement were produced by a liquid infiltration process, severe interface reaction would be probably inevitable.
Esen et al. [73] fabricated $\mathrm{NiTi}_{\mathrm{p}} / \mathrm{Mg}$ matrix composites by rotary hot swaging and post-annealing heat treatment. First, mixed $\mathrm{Mg}$ and TiNi powders were loaded into thinwalled copper cylindrical vessels. Subsequently, the powder-filled vessels were evacuated and tightly closed, and vessels were deformed using a rotary swaging technique, in which both heat and deformation were applied simultaneously, and an annealing heat treatment was carried out at $600{ }^{\circ} \mathrm{C}$ for $90 \mathrm{~min}$ to homogenize the heavily deformed structures. The $\mathrm{Mg}$ matrix contained elongated grains comprised of equiaxed recrystallized grains (Fig. 27), and the TiNip preserved their starting spherical shape during processing. They reported that the TiNi particles were debonded during mechanical testing due to insufficient bonding between the $\mathrm{NiTi}_{\mathrm{p}}$ and $\mathrm{Mg}$ matrix and fracture resulted largely from the oxide layers present in the interfacial region and the magnesium oxide film in the grain boundaries.

So far, few researches on Ti-matrix composites reinforced by SMA reinforcements are reported. A Ti-matrix composite with reinforcements of TiPdNiW SMA was fabricated by sheath rolling of the alternatively laminated SMA and Ti-matrix plates [74]. Figure 28 shows the schematic of the processing. No debonding was detected at and near interface areas, but a multi-layered interface structure with a $30 \mu \mathrm{m}$-thick reaction layer was found between the SMA plate and Ti plates. This study shows that it is possible to produce a SMA/Ti composite at a relatively low temperature.

Except for the SMA-reinforced $\mathrm{Al}, \mathrm{Mg}$, and $\mathrm{Ti}$ composites, investigation on SMA-reinforced metals with low melting points are also reported recently. For example, CuAlNi particles reinforced $\mathrm{In}$ and $(\mathrm{In}+\mathrm{Sn})$ alloys were 
Table 3 Summary of AMCs reinforced with SMA particles and their fabrication methods

\begin{tabular}{|c|c|c|c|c|c|}
\hline Matrix & $\begin{array}{l}\text { Reinforcement } \\
\text { (vol \%) }\end{array}$ & Fabrication method & Temperature/pressure & Interface & Ref \\
\hline Pure Al & $\operatorname{NiTi}_{\mathrm{p}}(2,4)$ & Hot pressing & $\begin{array}{l}70 \mathrm{MPa} \text { cool press } \\
673 \mathrm{~K} \text { extruded }\end{array}$ & Unknown & {$[21]$} \\
\hline Pure Al & $\operatorname{NiTi}_{\mathrm{p}}(3,5,8)$ & Plasma activated sintering & $273-853 \mathrm{~K} / 0-39 \mathrm{MPa}$ & $1.2 \mu \mathrm{m}$ layer & {$[22]$} \\
\hline Pure Al & $\mathrm{TiNiCu}_{\mathrm{p}}(20)$ & Mechanically alloying + swaged & rolled at $723 \mathrm{~K}$ & Unknown & {$[55$} \\
\hline Pure Al & $\mathrm{TiNiCu}_{\mathrm{p}}(30)$ & Hot isostatic pressing & $793 \mathrm{~K}$ & Unknown & {$[56]$} \\
\hline Pure Al & $\mathrm{TiNiCu}_{\mathrm{p}}(30)$ & Hot processing & $\begin{array}{l}723 \mathrm{~K} / 40-50 \mathrm{MPa} \text {, extruded } \\
\text { at } 753 \mathrm{~K}\end{array}$ & $\mathrm{Al}_{3} \mathrm{Ti}, \mathrm{Al}_{3} \mathrm{Ni}$ & {$[57]$} \\
\hline 1090Al & $\operatorname{NiTi}_{\mathrm{p}}(10)$ & Hot pressing & $823 \mathrm{~K}$ & Unknown & {$[58]$} \\
\hline $2124 \mathrm{Al}$ & $\operatorname{NiTi}_{p}(10,20)$ & Hot pressing and extrusion & $773 \mathrm{~K} / 90 \mathrm{~min}$ extruded at $753 \mathrm{~K}$ & $\begin{array}{l}\text { Three-layers: } \mathrm{Al}_{3} \mathrm{Ni}, \mathrm{Al}_{3} \mathrm{Ti} \text {, } \\
\text { Al-rich layer }\end{array}$ & {$[59]$} \\
\hline $2124 \mathrm{Al}$ & $\operatorname{NiTi}_{\mathrm{p}}(10,20)$ & Hot pressing and extrusion & $773 \mathrm{~K} / 15$ min extruded at $703 \mathrm{~K}$ & No & {$[60]$} \\
\hline Al & $\mathrm{NiTi}_{\mathrm{p}}(36)$ & $\begin{array}{l}\text { Self-propagating } \\
\text { high-temperature } \\
\text { synthesis porous TiNi }\end{array}$ & Infiltrated liquid $\mathrm{Al}$ at $1,023 \mathrm{~K}$ & $\begin{array}{l}\mathrm{Ni}_{3}(\mathrm{AlTi}), \mathrm{AlNi}_{2} \mathrm{Ti} \\
\mathrm{Ti}_{2} \mathrm{Ni}, \mathrm{TiNi}_{3}\end{array}$ & {$[61]$} \\
\hline $1100 \mathrm{Al}$ & $\mathrm{NiTi}_{\mathrm{p}}(-)$ & Friction stir processing & - & No & {$[62]$} \\
\hline $6061 \mathrm{Al}$ & $\operatorname{NiTi}_{\mathrm{p}}(10)$ & Friction stir processing & - & No & {$[63]$} \\
\hline
\end{tabular}

successfully fabricated [75-79]. An amount (around 50-60 vol\%) of CuAlNi powders were selected and degassed in a tube under vacuum. Then, a metal matrix of In or In-Sn alloy was infiltrated at a temperature higher than matrix melting temperature $(\sim 500 \mathrm{~K})$ under a moderate pressure $(0.3-0.4 \mathrm{MPa})$ for a short time. Figure 29 shows the microstructure of the $\mathrm{CuAlNi} /(\mathrm{In}-\mathrm{Sn})$ composites. Relatively good wetting of the SMA particles could be observed in the composites, and good adhesion was also observed. Generally, owing to the especially low fabrication temperature and short processing time, the interface reaction hardly took place. However, it was confirmed that $\mathrm{Cu}$ dissolved from the $\mathrm{CuAlNi}$ particles into both phases of the InSn matrix, and the higher the Sn content of the matrix, the stronger the interaction with the CuAlNi particles [77]. It seemed that $10 \mathrm{~min}$ at $473 \mathrm{~K}$ is enough to dissolve a certain amount of $\mathrm{Cu}$ from the $\mathrm{CuAlNi}$ particles into the molten eutectic matrix [77]. The produced SMA composites exhibited very high damping capacity in a relatively wide range of temperature, and the composite produced with the InSn eutectic matrix shows the highest damping coefficient [78, 79].

\section{Physical and Mechanical Property}

\subsection{Phase Transformation during Heating Cycle}

It was reported that $\mathrm{AMC}$ reinforced by $\mathrm{NiTi}_{\mathrm{f}}$ exhibited a pronounced, nonlinear thermal contraction during the unconstrained heating process from room temperature to $120{ }^{\circ} \mathrm{C}$ (Fig. 30), while the homogeneous control exhibited the expected linear thermal expansion [26, 27, 29-34]. This indicates the development of an increasing matrix compression stress by a martensite to austenite shape recovery transformation in the reinforcement. The thermal compression is clearly the result of a powerful shape memory response in the actuating $\mathrm{NiTi}_{\mathrm{f}}$. It therefore appears that the basic mechanism of the NiTi shape memory transformation did not significantly change during the unconstrained heating process.

The stress of the fiber in the composite strongly increased with increasing temperature until approximately $100{ }^{\circ} \mathrm{C}$. Beyond this temperature, it appears that the transformation stress in the fiber saturated to a value that is approximately equal to the high-temperature transformation limit strength of the extracted $\mathrm{NiTi}_{\mathrm{f}}$ (750 MPa) [29]. It was also reported that a suitable prestrain process on the SMA/metal composites will exhibit a very large thermal compression response during a subsequent external stressfree heating process $[33,34]$. This very large thermal compression response is the result of the shape memory response of the $\mathrm{NiTi}_{\mathrm{f}}$, which causes large plastic compression flow in the matrix. The thermal compression response is shifted to higher temperatures with increasing maximum room-temperature tensile strain.

Investigation on the reverse martensitic transformation of $\mathrm{TiNi}_{\mathrm{f}} / \mathrm{Al}$ composite showed that under the influence of temperature and recovery stress, the reverse martensitic transformation of $\mathrm{TiNi}_{\mathrm{f}}$ can be divided into two parts with different kinetic characteristics: the reverse transformation of self-accommodating martensite and that of oriented martensite [25, 40, 42, 43]. For the $\mathrm{TiNi}_{\mathrm{f}} / \mathrm{Al}$ composite deformed in the martensite state, one endothermic peak 

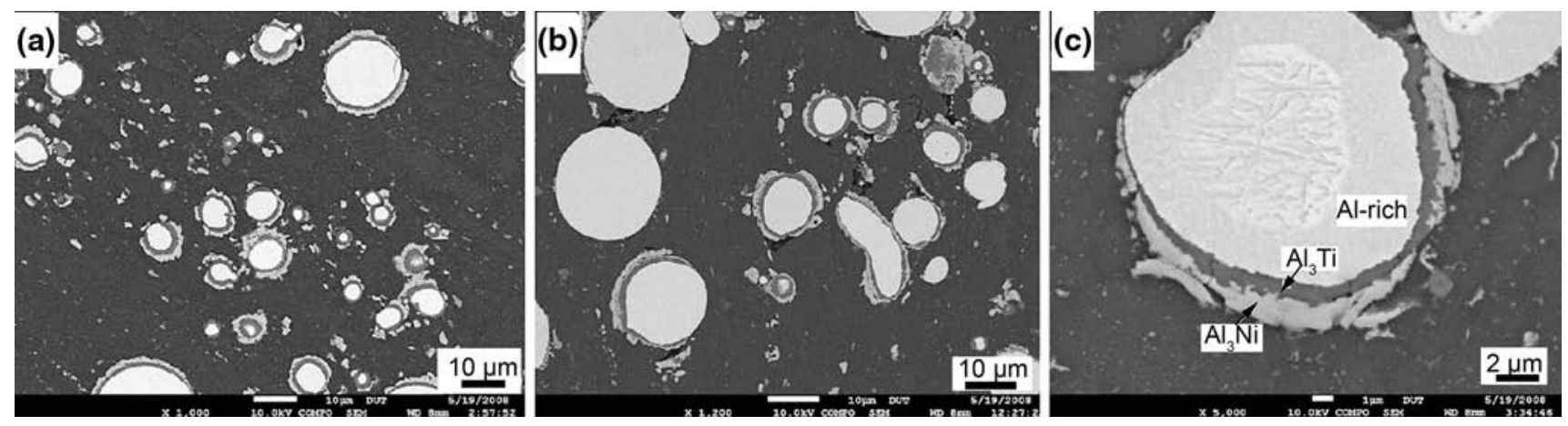

Fig. $17 \mathrm{SEM}$ backscatter electron images of $\mathrm{NiTi}_{\mathrm{p}} / 2124 \mathrm{Al}$ composite sintered at $500{ }^{\circ} \mathrm{C}$ for 90 min: a 10 vol\% $\mathrm{NiTi}_{\mathrm{p}}$; b $20 \mathrm{vol} \% \mathrm{NiTi}_{\mathrm{p}}$; c detailed interfacial microstructure [59]
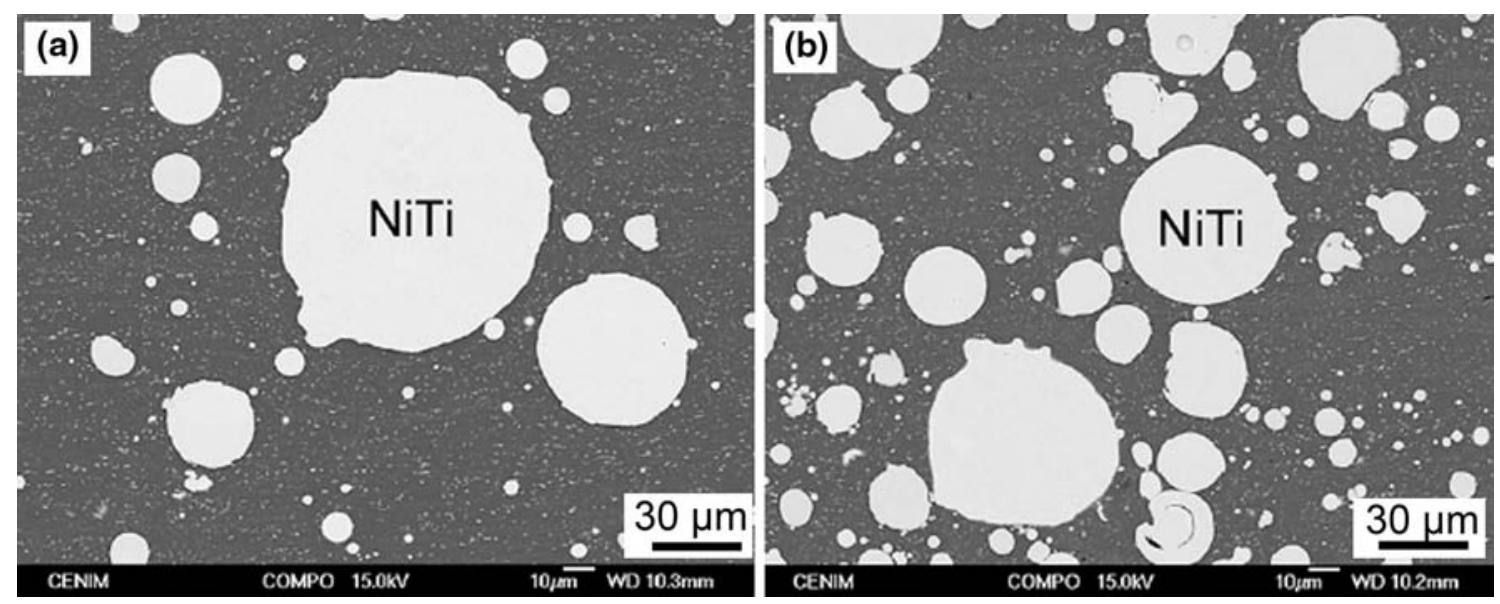

Fig. $18 \mathrm{SEM}$ backscatter electron images of $\mathrm{NiTi}_{\mathrm{p}} / 2124 \mathrm{Al}$ composite sintered at $500{ }^{\circ} \mathrm{C}$ for 15 min: a 10 vol\% $\mathrm{NiTi}_{\mathrm{p}}$; b $20 \mathrm{vol} \% \mathrm{NiTi}_{\mathrm{p}}$ [60]

appears on the DSC curve as shown in Fig. 31, and the peak shifts to higher temperature and its area decreases with increasing of the prestrain level. This phenomenon is similar to that observed in the $\mathrm{NiTi}_{\mathrm{f}} / 6061 \mathrm{Al}$ and $\mathrm{NiTi}_{\mathrm{f}} /$ 6082Al composites [33, 34].

For the SMA particle-reinforced AMC, it was reported that both the as-received $\mathrm{TiNiCu}$ particles and the $\mathrm{TiNiCu} / \mathrm{Al}$ composite showed reversible thermoelastic martensitic transformations as in the bulk material [56]. The $\mathrm{NiTi}_{\mathrm{p}} /$ 6061 Al composite fabricated by FSP and the as-received $\mathrm{NiTi}_{\mathrm{p}}$ also exhibited a similar phase transformation behavior during the heating and cooling cycles (Fig. 32) [63].

\subsection{Damping Property}

The SMA-like NiTi shows the stiffness change and high damping in the martensite phase at lower temperatures below $M_{\mathrm{f}}$, suggesting the SMA/Al composite can have a possibility of improvement in the damping capacity in comparison with the unreinforced $\mathrm{Al}$ marix.
It was reported that a $\mathrm{NiTi}_{\mathrm{f}} / \mathrm{Al}$ composite with two different volume fractions of 0.4 and $0.7 \%$ showed an improved damping capacity $(\tan \delta)$ over the unreinforced Al matrix in the range of 273-423 K [18]. This improvement was thought to be caused mainly by the difference of the stiffnesses between the $\mathrm{TiNi}_{\mathrm{f}}$ and the $\mathrm{Al}$ matrix. Moreover, the distinct drop of the $\tan \delta$ was observed with increasing temperature, which seems to be related with the decrease of the high damping of the $\mathrm{NiTi}_{\mathrm{f}}$ above austenite start temperature $\left(A_{\mathrm{s}}\right)$. It was confirmed that the damping property of the $\mathrm{TiNi}_{\mathrm{f}} / \mathrm{Al}$ composite was improved owing to the two effects relating to (1) stiffness gap between TiNi fiber and $\mathrm{Al}$ matrix as well as (2) changes of damping capacity associated with thermal transformation of embedded SMA fibers [18].

Armstrong et al. [31] studied the damping property of a $\mathrm{NiTi}_{\mathrm{f}} / 6082-\mathrm{T} 6$ composite at low temperature of 20,4 , and $20 \mathrm{~K}$. A significant increase in damping below $4 \mathrm{~K}$ was attributed to the sub-saturation martensite variant reorientation processes within the $\mathrm{NiTi}_{\mathrm{f}}$, and a small increase in 

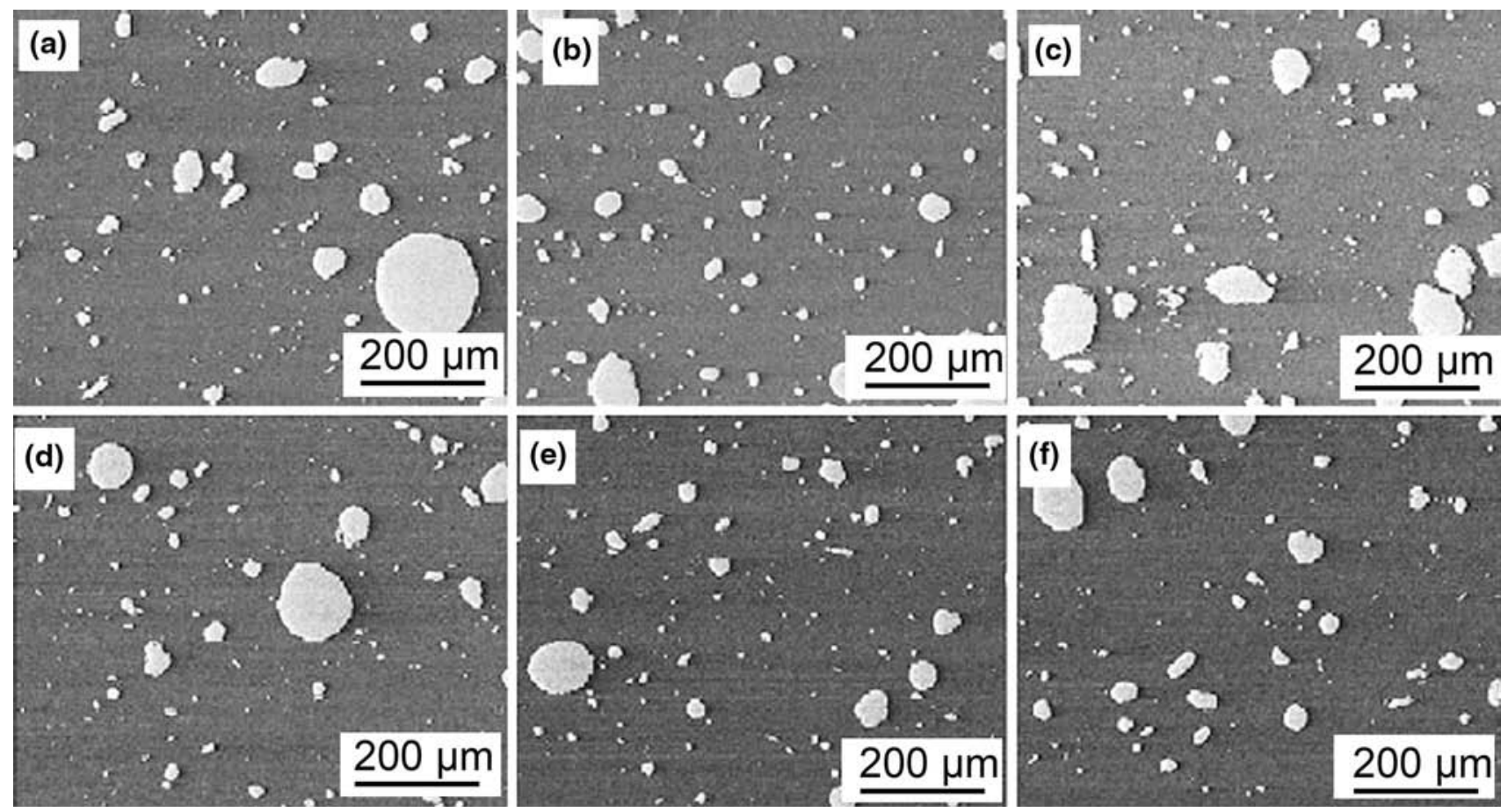

Fig. 19 SEM images showing uniformly distributed $\mathrm{NiTi}_{\mathrm{p}}$ in FSP composites a-c and of annealed composites $\mathbf{d}-\mathbf{f}$ [62]

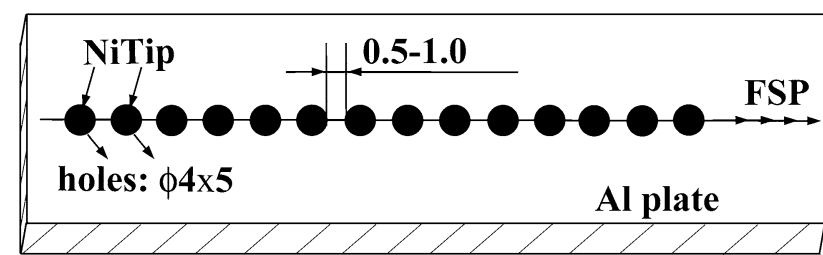

Fig. 20 Schematic diagram of preparing bulk $\mathrm{NiTi}_{\mathrm{p}} / 6061 \mathrm{Al}$ composites by FSP (unit: $\mathrm{mm}$ ) [63]

the stiffness of the beam was observed, which is similar to that of [19]. Similar to the AMC with reinforcement of SMA fiber, SMA particles reinforced MMCs also showed good damping properties, such as $\mathrm{NiTi}_{\mathrm{p}}$ reinforced $2124 \mathrm{Al}$ composite [59, 60], and CuAlNi particles reinforced In and $(\mathrm{In}+\mathrm{Sn})$ matrix composites $[75,76,78]$.

Besides, a porous TiNi matrix composite (about $64 \mathrm{vol} \%$ porosity) reinforced with infiltrated $\mathrm{Al}$ alloy showed about $70 \%$ of the specific damping capacity of the TiNi ingot, which is about three times higher than the calculated value [61]. Figure 33 shows a comparison of the specific damping capacity for various materials, and the material with higher specific damping capacity shows superior damping properties. $\mathrm{Al}$ and steel have low specific damping capacity, but TiNi SMA has a high specific damping capacity due to the existence of martensite in TiNi. The enhanced damping properties result from the martensite twin in the interior of TiNi and between plates.
In addition to the martensite twins in the TiNi phase, the $\mathrm{Al} / \mathrm{TiNi}$ composites have numerous phase boundaries between $\mathrm{Al}$ and TiNi. It is considered that the improved damping properties of the Al/TiNi composites are attributed to the phase boundaries between $\mathrm{Al}$ and $\mathrm{TiNi}$ and ternary phase precipitation in the $\mathrm{Al}$ matrix in spite of the decrease in the fraction of martensite TiNi phase.

\subsection{Tensile Property}

A comparison between the cases of the $9 \mathrm{vol} \% \mathrm{NiTi}_{\mathrm{f}}$ reinforced $1100 \mathrm{Al}$ composite with $4 \%$ prestrain and without prestrain clearly indicated the SME (Fig. 34) [18, 19]; the tensile flow stress of the composite with prestrain improved over that without the prestrain. The tensile properties were improved by strengthening mechanism of thermoelastic SME of $\mathrm{NiTi}_{\mathrm{f}}$, and the increases in Young's modulus, yielding stress and work-hardening rate depend on the volume fraction of $\mathrm{NiTi}_{\mathrm{f}}$, and the yield stress also depend on prestrain. Similar results were found in a $\mathrm{NiTi}_{\mathrm{f}} /$ 1060Al composite [24].

The self-strengthening mechanism generated in most $\mathrm{NiTi}_{\mathrm{f}} / \mathrm{Al}$ composites showed that shape memory recovery force in $\mathrm{NiTi}_{\mathrm{f}}$ works more strongly at a higher temperature than at room temperature [19, 26-30, 32, 37, 49], except the $\mathrm{NiTi}_{\mathrm{f}} / 1060 \mathrm{Al}$ composite [24]. This increase was due to the imposition of a large longitudinal compressive stress in the matrix by the $\mathrm{NiTi}_{\mathrm{f}}$ shape memory response, and due to the increase in $\mathrm{NiTi}_{\mathrm{f}}$ transformation 

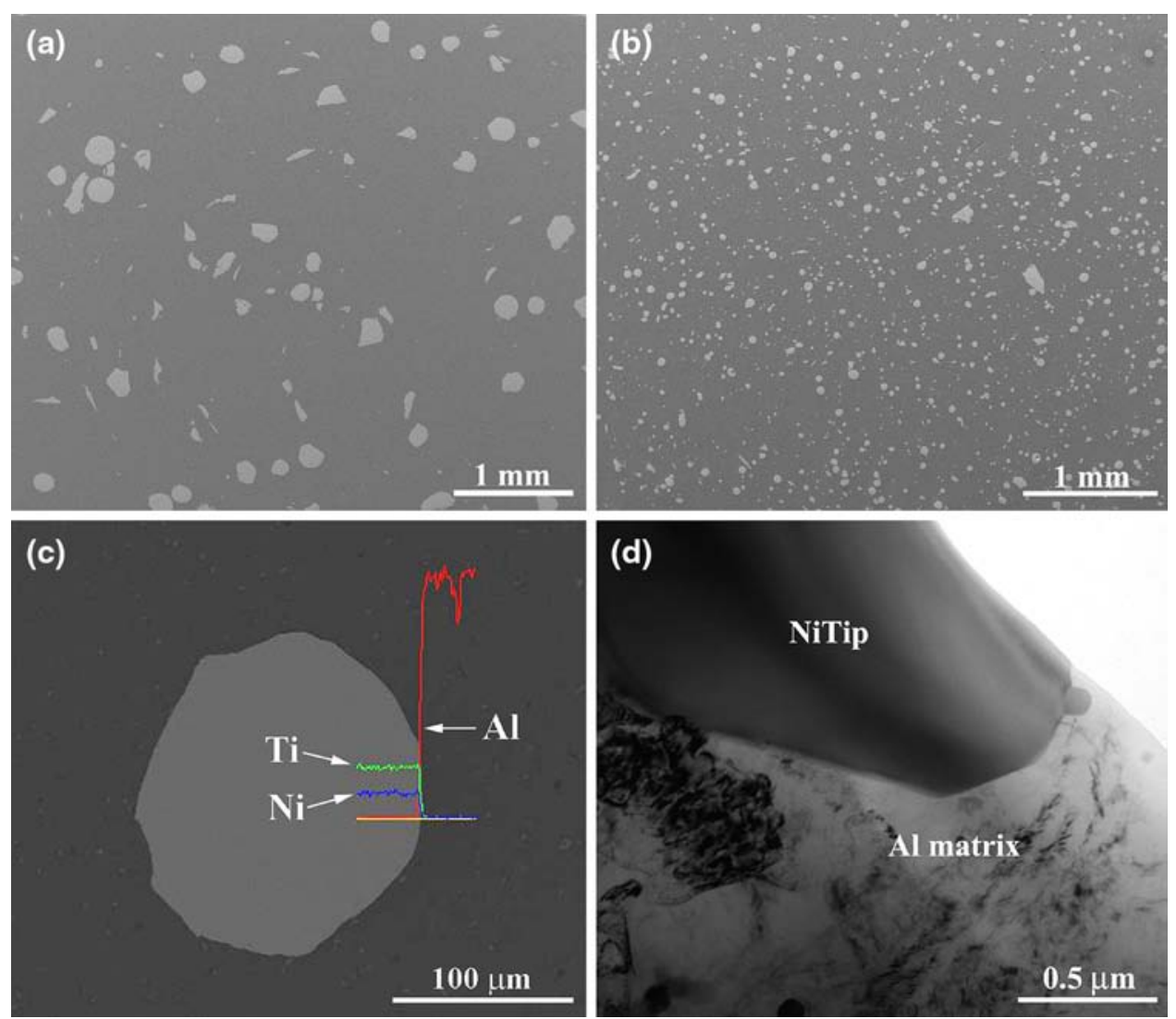

Fig. 21 SEM images showing uniform distributions of $\mathrm{NiTi}_{\mathrm{p}}$ in large a and small b NiTi $\mathrm{p}_{\mathrm{p}}$ reinforced $6061 \mathrm{Al}$ composite, backscattered electron (BSE) image and EDS line scan showing no interfacial reaction $\mathbf{c}$ and TEM image showing no interfacial reaction $\mathbf{d}$ [63]
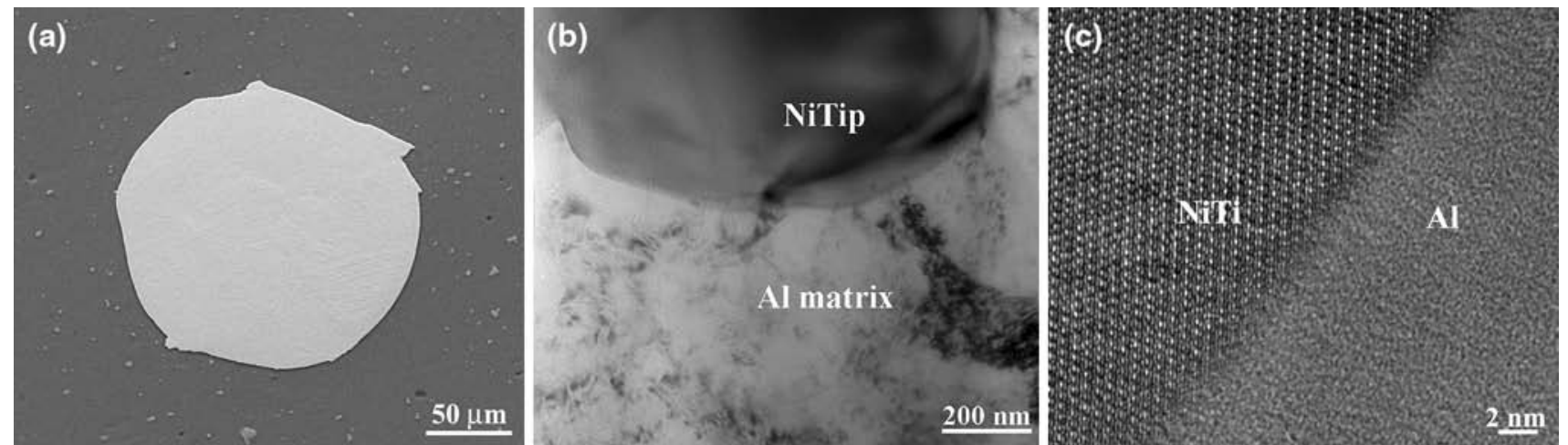

Fig. 22 Microstructure of $\mathrm{NiTi}_{\mathrm{p}} / 6061 \mathrm{Al}$ composite after $\mathrm{T} 6$ heat treatment showing no interfacial reaction: a SEM image; b TEM image; c HRTEM image [63]

stress with increased temperature. It was reported that the tensile strength of a prestrained composite increased as the amount of prestrain increased at high temperature. However, the amount of increase of strength does not increase noticeably as the amount of prestrain increases at room temperature [37].

It should be noted that the SMA-matrix interface may greatly influence the strength of the SMA/metal composites. For the $\mathrm{TiNi}_{\mathrm{f}} / \mathrm{Al}$ composite reinforced by pre-oxidated
$\mathrm{TiNi}_{\mathrm{f}}$ [24], with increase in oxidation time, the thickness of the interfacial layers between TiNi fiber and Al matrix increased, and the tensile strength and elongation of the composite decreased. When the oxidation time was $1 \mathrm{~h}$, about 1- $\mu$ m-thick interfacial layer was formed, resulting in the strong interfacial bonding between $\mathrm{Al}$ matrix and $\mathrm{TiNi}_{\mathrm{f}}$. In this case, the tensile strength of the composite is very close to the theoretical value $(272 \mathrm{MPa})$ at room temperature. 
Table 4 Summary of Mg, Ti, and In alloy-based MMCs reinforced with SMA

\begin{tabular}{|c|c|c|c|c|c|}
\hline Matrix & Reinforcement (vol\%) & Fabrication method & Temperature/pressure & Interface & Ref. \\
\hline AZ31 Mg & $\mathrm{NiTi}_{\mathrm{f}}(20)$ & Pulsed current hot pressing & $773 \mathrm{~K} / 32 \mathrm{MPa}$ & $12 \mu \mathrm{m}$ layer & {$[69,70]$} \\
\hline $\mathrm{Mg}$ & $\mathrm{NiTi}_{\mathrm{f}}(-)$ & Hot-pressing process & $593 \mathrm{~K} / 375 \mathrm{MPa}$ & No & {$[71]$} \\
\hline $\mathrm{Mg}$ & Porosity NiTi (-) & $\begin{array}{l}\text { Pore-forming technique, } \\
\text { powder sintering }\end{array}$ & $\begin{array}{l}\text { Infiltrated liquid } \\
\mathrm{Mg} \text { at } 973 \mathrm{~K}\end{array}$ & $\mathrm{Mg}_{2} \mathrm{Ni}, \mathrm{MgO}$ & {$[72]$} \\
\hline $\mathrm{Mg}$ & $\mathrm{NiTi}_{\mathrm{p}}(5)$ & $\begin{array}{l}\text { Rotary hot swaging and } \\
\text { post-annealing heat } \\
\text { treatment }\end{array}$ & $\begin{array}{l}723 \mathrm{~K} \text { press } \\
873 \mathrm{~K} \text { heat }\end{array}$ & 90-100 nm layer, $\mathrm{MgO}$ & [73] \\
\hline $\mathrm{Ti}$ & TiPdNiW plates $(-)$ & Sheath rolling & $1,223 \mathrm{~K}$ & $30 \mu \mathrm{m}$ layer & [74] \\
\hline $\mathrm{In} /(\mathrm{In}+\mathrm{Sn})$ & $\mathrm{CuAlNi}_{\mathrm{p}}(60)$ & Infiltrated & $<500 \mathrm{~K}$ & No & {$[75-79]$} \\
\hline
\end{tabular}

\subsection{Fatigue Property}

The suppression effect of SME on the fatigue crack propagation of a $\mathrm{NiTi}_{\mathrm{f}} / \mathrm{Al}$ composite has been carefully investigated [19]. The results showed that crack propagation rate was decreased by the heat up of the specimen (Fig. 35a), and a distinct and drastic drop of $\mathrm{d} a / \mathrm{d} N$ was observed in the part immediately after the increase of specimen temperature to $90{ }^{\circ} \mathrm{C}\left(>A_{\mathrm{f}}\right.$ ) (Fig. 35b). This phenomenon seems to be caused by shape memory shrinkages of $\mathrm{NiTi}_{\mathrm{f}}$ and the following crack-tip suppression effect by the compressive stresses at the crack-tip where the embedded $\mathrm{NiTi}_{\mathrm{f}}$ have been already plastically deformed. This phenomenon is very similar to the fatigue crack growth retardation immediately after a spike overload which is generally thought to be caused by the crack-closure effect owing to the large residual stresses in the newly formed large local plastic zone around an overloaded fatigue crack-tip.

The fatigue property of a TiNi/ $6061 \mathrm{Al}$ composite with various contents of $\mathrm{NiTi}_{\mathrm{f}}$ and a reduction of area was investigated under both room temperature and high-temperature conditions (Fig. 36) [38]. The delay in crack propagation was not so large at room temperature, but it was clear at high temperature. The effect of compressive residual stress and the stress reduction effect ahead of the crack-tip occurring within the matrix acts largely at high temperature due to local shape memory shrinkage and the difference in the thermal expansion coefficient of the $\mathrm{TiNi}_{\mathrm{f}}$ and Al matrix. The crack retardation effect of the coldrolled composite was higher than that of the nonrolled composite at high temperature due to the residual compressive stress effect in the matrix. The most optimal condition for manufacturing of the fatigue limit is when the volume ratio is $5 \%$ and the reduction ratio is 10\% [39].

Similarly, SMA particles reinforced AMC also showed good fatigue property. For example, $10 \mathrm{vol} \% \mathrm{NiTi}_{\mathrm{p}} /$ 1090Al composite displayed a remarkable amplification of both the peak-stress capability and the fatigue life [58]. At the higher stress levels, the composites had a decidedly longer life than the unreinforced matrix. Note especially at the peak stress, where the matrix material can only withstand 50 cycles until failure, while the composite retains its integrity for 150,000 cycles. The increased fatigue life at higher stress levels is due possibly to a stress-induced phase transformation in the shape memory particles.

\subsection{Wear Property}

The sliding wear behavior of a 30 vol\% Ti50Ni25Cu25 particle-reinforced AMC under dry conditions was investigated with a 10 vol\% $\mathrm{SiC}_{\mathrm{p}} / \mathrm{Al}$ composite and pure $\mathrm{Al}$ chosen as the comparison specimens [57]. The results indicate that the $\mathrm{TiNiCu} / \mathrm{Al}$ composite exhibited higher wear resistance than the unreinforced matrix and are comparable with the $10 \mathrm{vol} \% \mathrm{SiC}_{\mathrm{p}} / \mathrm{Al}$ composite; meanwhile, the interfacial reaction was a predominant factor in determining the wear behavior of the $\mathrm{TiNiCu} / \mathrm{Al}$ composite. A self-adaptive mechanism of heat absorption by the reverse martensitic transformation and crack propagation suppression by stress-induced martensitic transformation in the SMA particles was proposed to contribute to enhancing the wear resistance of $\mathrm{TiNiCu} / \mathrm{Al}$ composites.

The wear characteristics of a $\mathrm{NiTi}_{\mathrm{f}} / 6061 \mathrm{Al}$ composite in dry sliding were also investigated with a $\mathrm{NiTi}_{\mathrm{f}} / 6061 \mathrm{Al}$ composite with $5 \mathrm{wt} \% \mathrm{SiCp}$ and monolithic $6061 \mathrm{Al}$ and $6061 \mathrm{Al}$ with $5 \mathrm{wt} \% \mathrm{SiC}_{\mathrm{p}}$ chosen as the comparison specimens (Fig. 37) [51]. The results showed samples with transverse fiber orientation show mostly abrasive wear; whereas, monolithic and parallel samples show adhesive wear mechanism. In addition, SiCp improved the wear resistance of the composite and the monolithic samples.

\section{Modeling and Numerical Study}

Several models to understand the strengthening mechanism of the SMA composite have been proposed, based on one- 


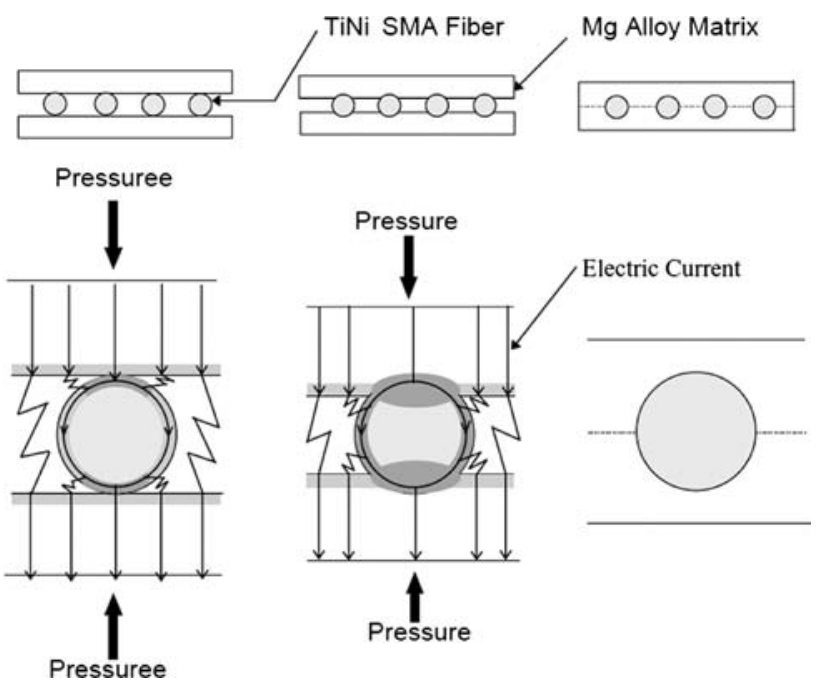

Fig. 23 Basic mechanism of bonding by spark discharge. Hatched areas are heated zones by spark discharge [69]

and three-dimensional approaches. The one-dimensional model was mainly targeted for the long fiber-reinforced composites. At the beginning, the three-dimensional

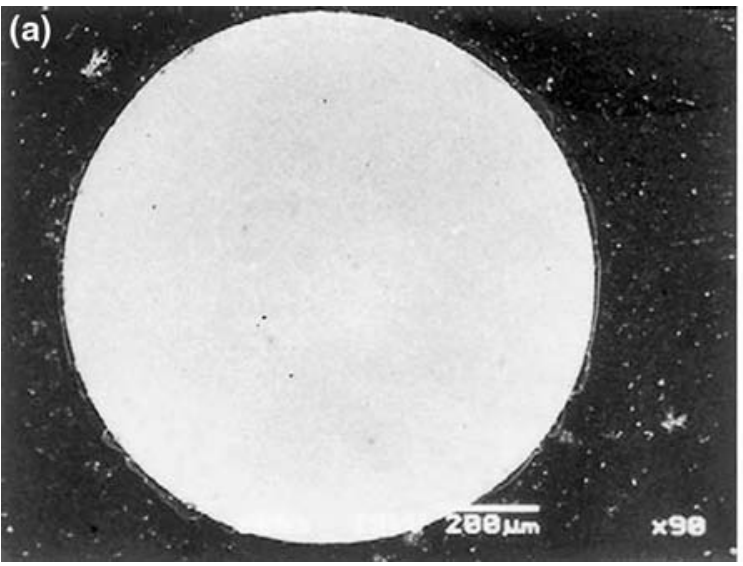

models were mainly focused on the particle-reinforced composites, then they were also adopted to analyze the long fiber-reinforced composites.

The strengthening of AMCs by the SME of dispersed SMA particles has been theoretically studied [20-22]. An analytical model was proposed for the prediction of the Young's modulus $(E)$, yield stress $\left(\sigma_{y}\right)$, and work-harding rate $\left(\bar{E}_{\mathrm{TC}}\right)$ on the bases of the Eshelby's equivalent inclusion method. The analysis was performed on the $\mathrm{NiTi}_{\mathrm{p}} / \mathrm{Al}$ composites with varying volume fractions and prestrains of the particles. The analysis indicated that the three parameters increase with increasing the volume fraction of the particles, and $\sigma_{\mathrm{y}}$ increase with increasing prestrain while $E$ and $\bar{E}_{\mathrm{TC}}$ are independent of prestrain. The residual stress caused by the shape memory of predeformed reinforcements contributes significantly to the strengthening of the composite. The analytical results of the composite yield stress based on the present model agree well with their experiment [22], and mainly agree with the experimental results of Ref. [23].

An analytical model for thermomechanical behavior of the composites was developed by utilizing an exponential

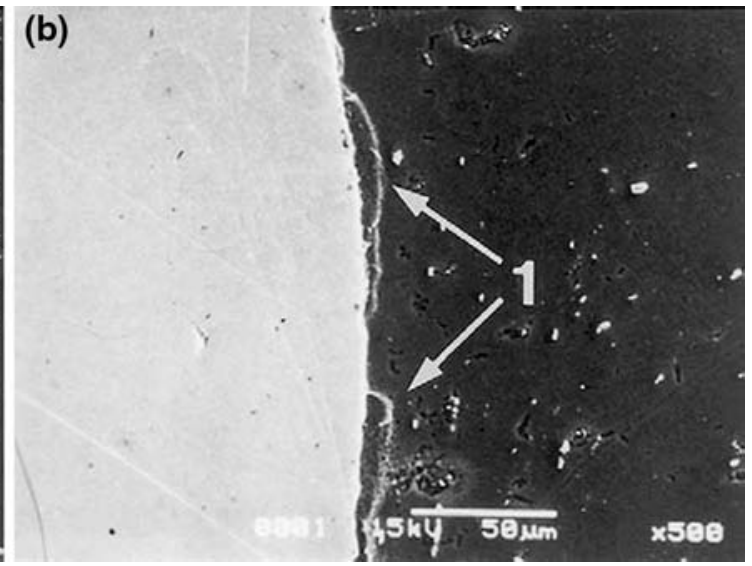

Fig. 24 a SEM micrograph of $\mathrm{NiTi}_{\mathrm{f}} / \mathrm{AZ31}$ composite fabricated by PCHP process; b SEM micrograph showing the white arrows show insufficient reacted areas between fiber and matrix (indicated by white arrows) [69]
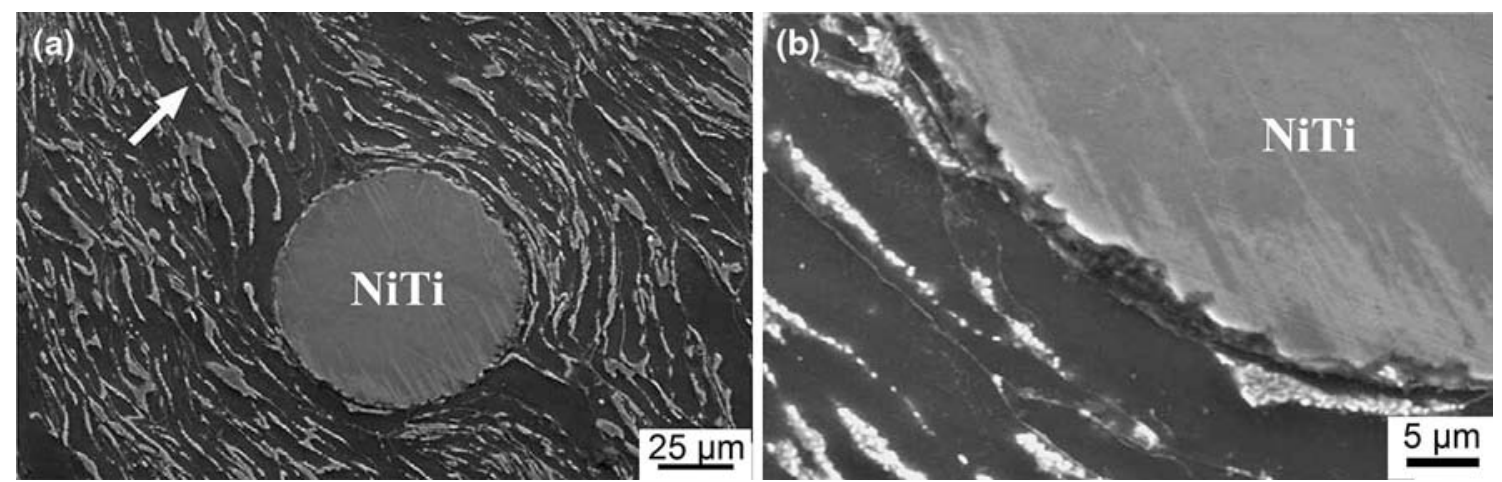

Fig. $25 \mathrm{SEM}$ micrographs of $\mathrm{TiNi}_{\mathrm{f}} / \mathrm{Mg}$ composite: a cross section of $\mathrm{TiNi}$, arrow denotes pressure direction of top punch, $\mathbf{b}$ magnified interfacial zone [71] 


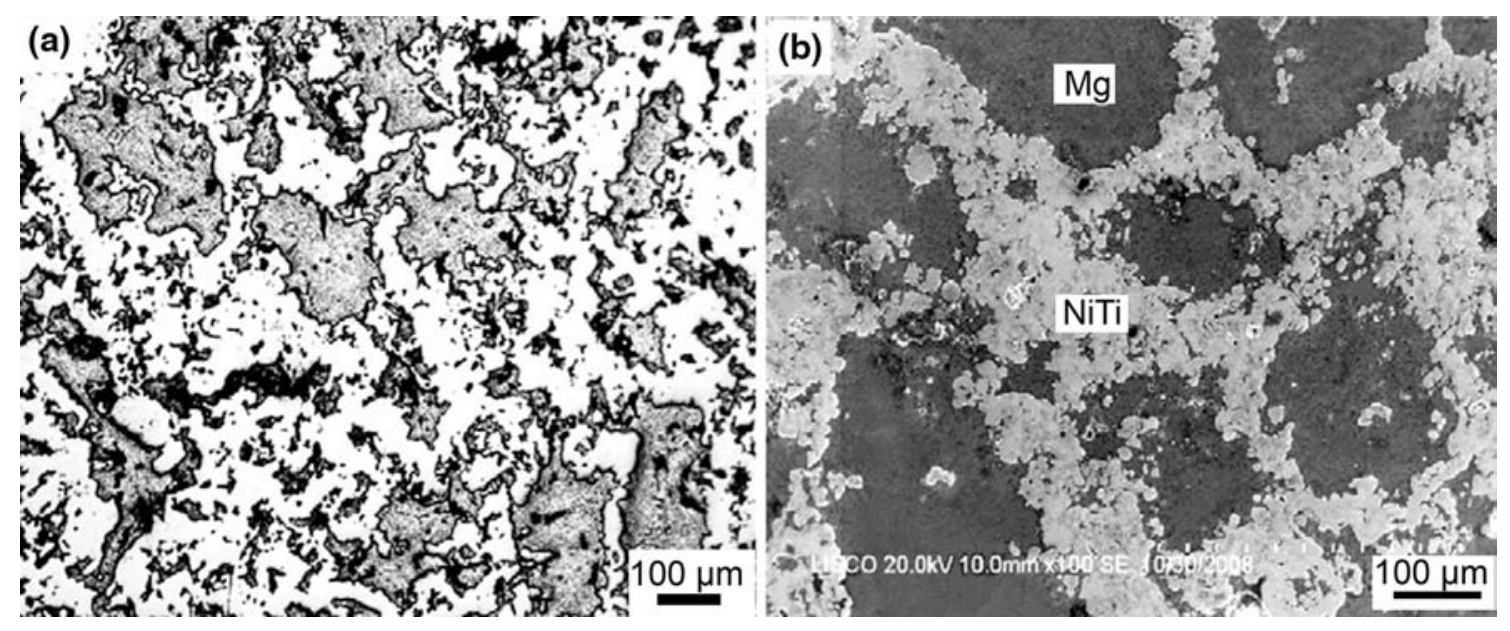

Fig. 26 Microstructures of Mg/NiTi composites a Sample A (optical micrograph); b Sample C (SEM) [72]
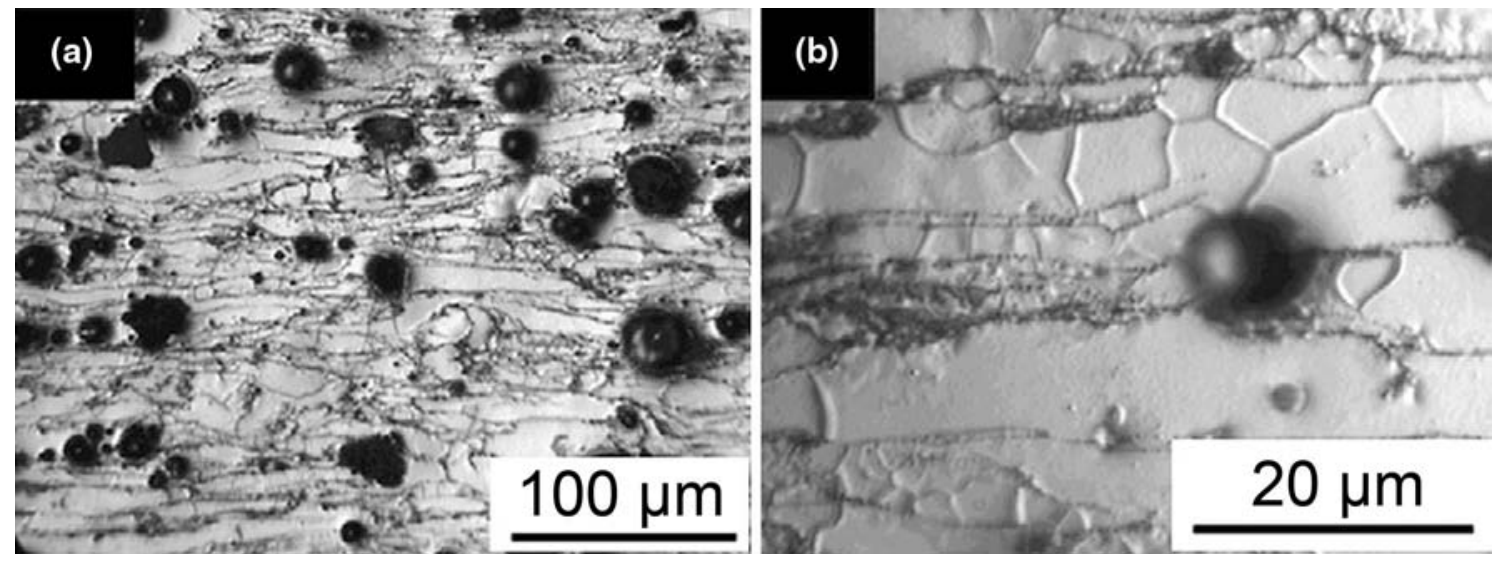

Fig. 27 Microstructures of $\mathrm{NiTi}_{\mathrm{p}} / \mathrm{Mg}$ parallel to swaging direction: a spherical $\mathrm{TiNi}_{\mathrm{p}}$ and elongated $\mathrm{Mg}$ grains; $\mathbf{b}$ recrystallized grains in elongated $\mathrm{Mg}$ grains [73]

type of SMA constitutive model [35]. The model predicts that the key parameters affecting the yield stress are the fiber volume fraction, prestrain, and matrix heat treatment, and it successfully predicts the observed yield stress dependency on the fiber volume fraction and prestrain, but underestimates the experimental results. The gap between the predicted and experimental yield stresses was explained by the dislocation punching during cooling process.

A nonlinear, one-dimensional composite constitutive model was proposed to analyze the experimental results of $\mathrm{NiTi}_{\mathrm{f}} / \mathrm{Al}$ composites [26, 27, 29]. The model provides a compact quantitative description of the thermal mechanical response of SMA/metal composites. The skew characteristics of the transformation probability fields result in the correct exhibition by the model of a number of important experimental features. However, this model does not account for the $25{ }^{\circ} \mathrm{C}$ tensile upper transformation point, and overestimates the elevated temperature yield strength of the composite. Further, three distinct thermal- mechanical processes were treated [80, 81]: an isothermal tensile loading-unloading process at the stress-free martensitic transformation start temperature, an external stressfree thermal process to a temperature above that required for the shape reverse transformation, and an isothermal loading at the thermal process finish temperature [80]; thereafter, a quantitative theory of the self-thermal-plastic response of NiTi actuated metal MMCs was developed [81]. The comparison between the model calculations and experimental data showed that the quantitative agreement between measured and calculated results is good at low and moderate temperatures but clear attenuation of the fibershape memory response appeared at temperatures above $100{ }^{\circ} \mathrm{C}$.

Pseudo-elasticity, shape memory, and strain hardening effects were taken into account to model the constitutive behavior of $\mathrm{NiTi}_{\mathrm{f}} / \mathrm{Al}$ composite along the fiber direction [82]. During phase transformation, the strain-temperature relation of $\mathrm{NiTi}_{\mathrm{f}}$ has been assumed to be linear. Hence, the 


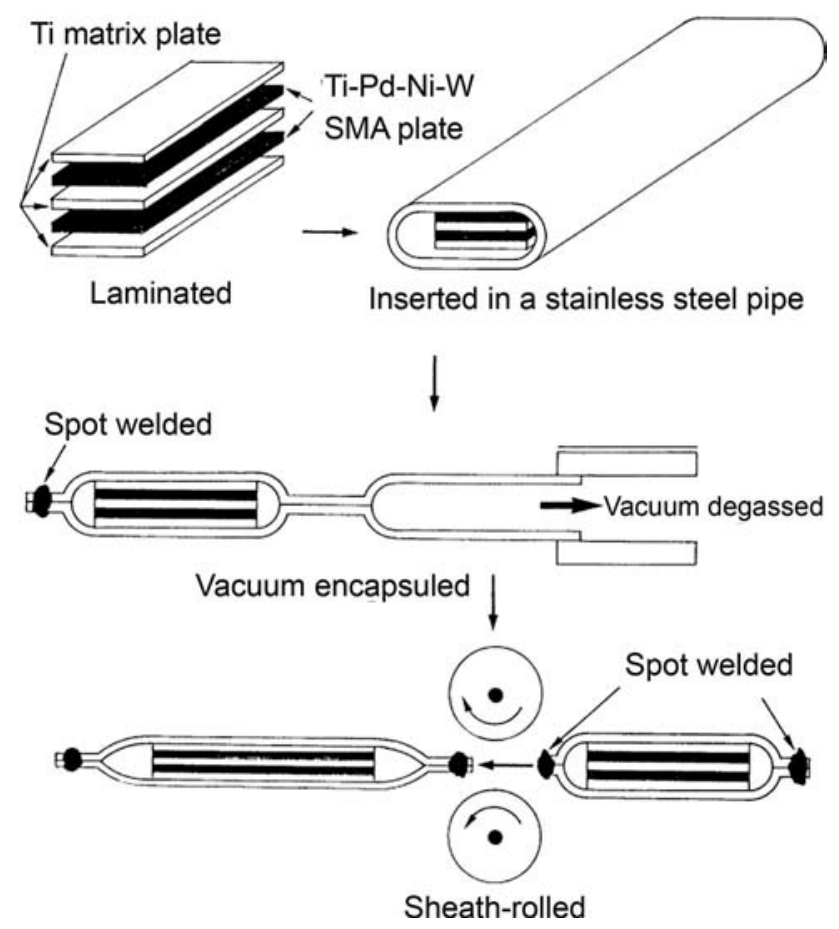

Fig. 28 Schematic illustration of sheath-rolling process [74]

incremental stress-strain relationship of the fibers has been derived for each temperature range where phase transformation takes place. As a result, a bi-linear and isotropic hardening elasto-plastic model was employed to describe the stress-strain relation of the Al matrix.

A micromechanics method based on the Mori-Tanaka averaging scheme was used to predict the effective thermomechanical properties of SMA fibers reinforced composite [83-85]. A 3D constitutive response for the SMA fibers was formulated first, and the composite transformation stress, the maximum transformation strain, and the hysteresis were computed. The results showed that shape recovery in the fibers may be enhanced or inhibited by the complex stress state induced by the effective loading path and eigenstresses [83]. For the two-way SME in a SMA fiber/elastomer matrix composite, processing-induced residual stresses alter the austenite start and martensite start temperatures, as well as the amount of strain recovered during a complete cycle of temperature and fiber martensite volume fraction [84, 85].

A quantitative micromechanics-based analysis on the role of microstructure and constituent properties was proposed in the overall behavior of SMA-reinforced composite [86, 87]. The macroscopic constitutive relations of the composite are established using self-consistent approach where the micro-macro correlation is realized by volume averaging and by introducing the concept of stress and strain concentration tensors. In this micromechanics modeling, the internal stress and strain in both matrix and SMA and their evolution are derived as function of externally applied thermomechanical loading as well as the degree of phase transformation in SMA [86].

A new 3D model for explaining the strengthening mechanism of the SMA composite was proposed, which incorporates Eshelbys inclusion theory, Mori-Tanaka mean field theory, and the stress and temperature-induced phase transformation of fibers in both tensile and compressive directions $[88,89]$. The predicted yield stresses of the SMA composite by the present model show good agreement with the experimental results by Hamada et al. [35], and shows better agreement than the one-dimensional model used by Hamada et al. [35].

Recently, a robust thermo-micromechanical framework to simulate the response of unidirectional SMA/epoxy and SMA/Al composite was developed [90]. This procedure accounts for the evolution of the one-way and the two-way SME in the SMA fiber, as well as the individual response of the matrix constituents. As a result, the thermomechanical macroscopic stress-strain-temperature relation of the composite as well as the local field distribution between the SMA fiber and its surrounding matrix can be established. The model predicted that a metallic matrix with lower coefficient of thermal expansion than that of the aluminum is possible to result in a better performance [90].
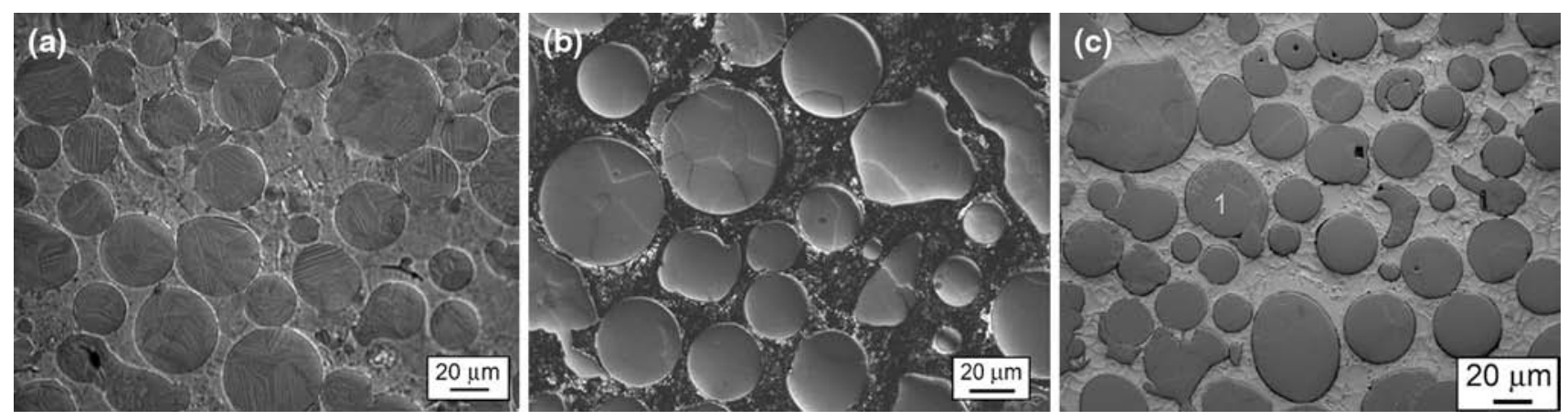

Fig. 29 Optical micrographs acquired using polarized light showing CuAlNi particles embedded in different matrices: a pure In; b In-10 wt $\%$ Sn; c In-49.1 wt\% Sn (eutectic) [77] 


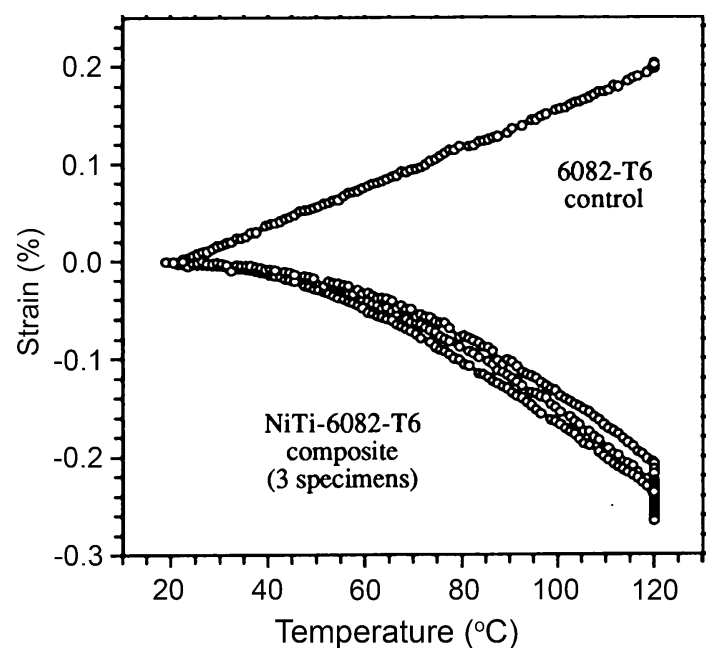

Fig. 30 Comparison between $\mathrm{NiTi} / 6082 \mathrm{Al}$ composites and 6082AlT6 control, $25-120{ }^{\circ} \mathrm{C}$ unconstrained heating process results [29]

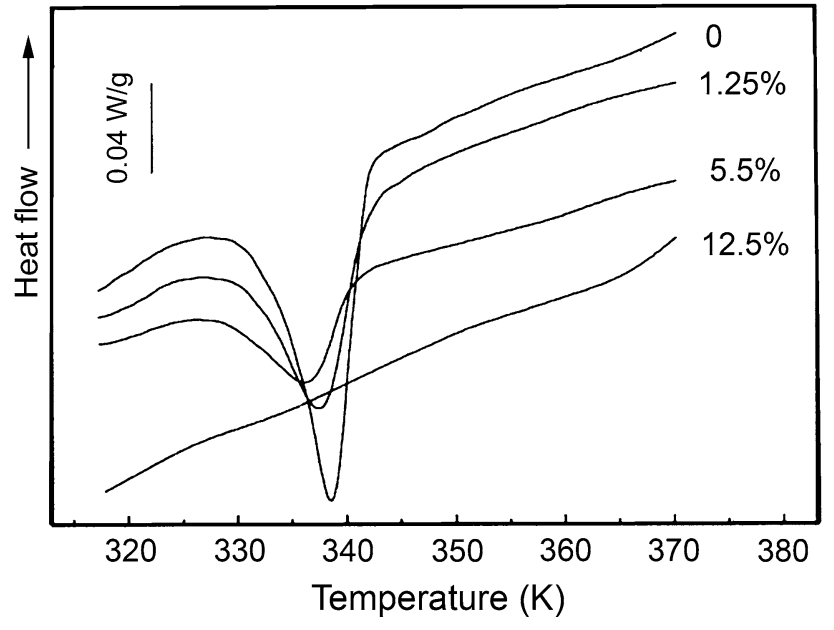

Fig. 31 DSC heating curves showing effect of prestrain on phase transformation of $\mathrm{TiNi}_{\mathrm{f}}$ embedded in $\mathrm{Al}$ matrix. [40]

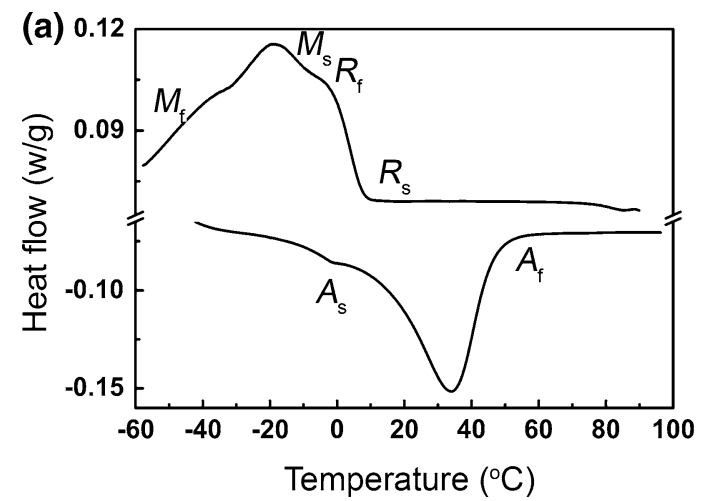

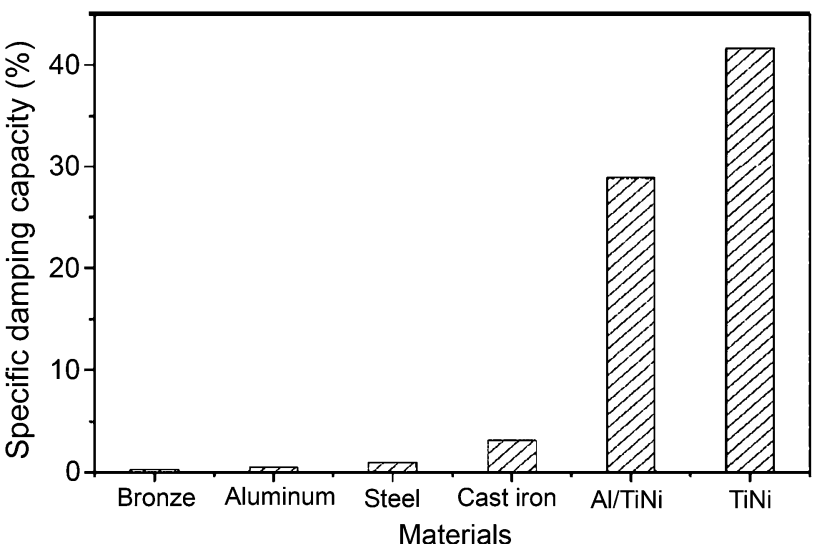

Fig. 33 Comparison of specific damping capacity for various materials [61]

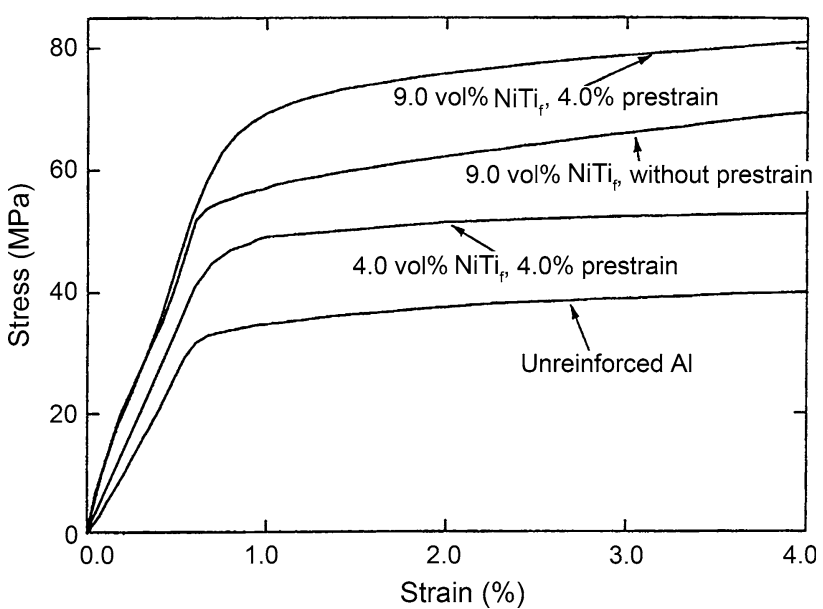

Fig. 34 Stress-strain curves measured at $363 \mathrm{~K}$ of unreinforced $\mathrm{Al}$ and $\mathrm{NiTi}_{\mathrm{f}} / \mathrm{Al}$ with $4.0 \%$ prestrain and without prestrain, $\mathrm{NiTi}_{\mathrm{f}}$ fraction of 4.0 and $9.0 \mathrm{vol} \%$ [18]

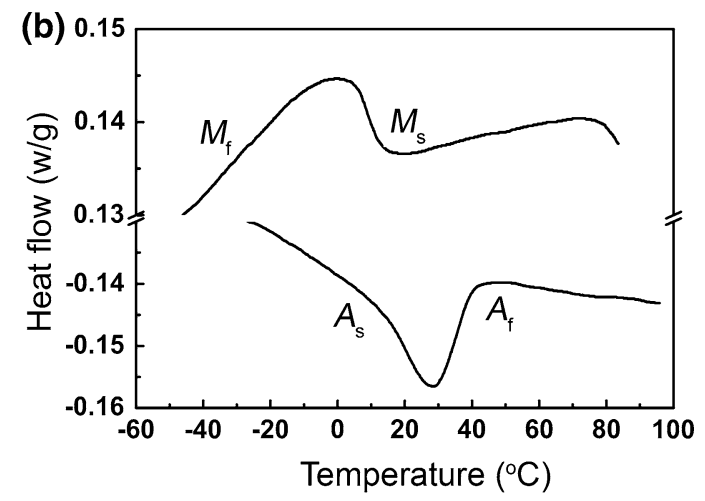

Fig. 32 DSC curves of as-received $\mathrm{NiTi}_{\mathrm{p}}$ a and $\mathrm{FSP} \mathrm{NiTi}_{\mathrm{p}} / 6061 \mathrm{Al}$ composite $\mathbf{b}$ [63] 

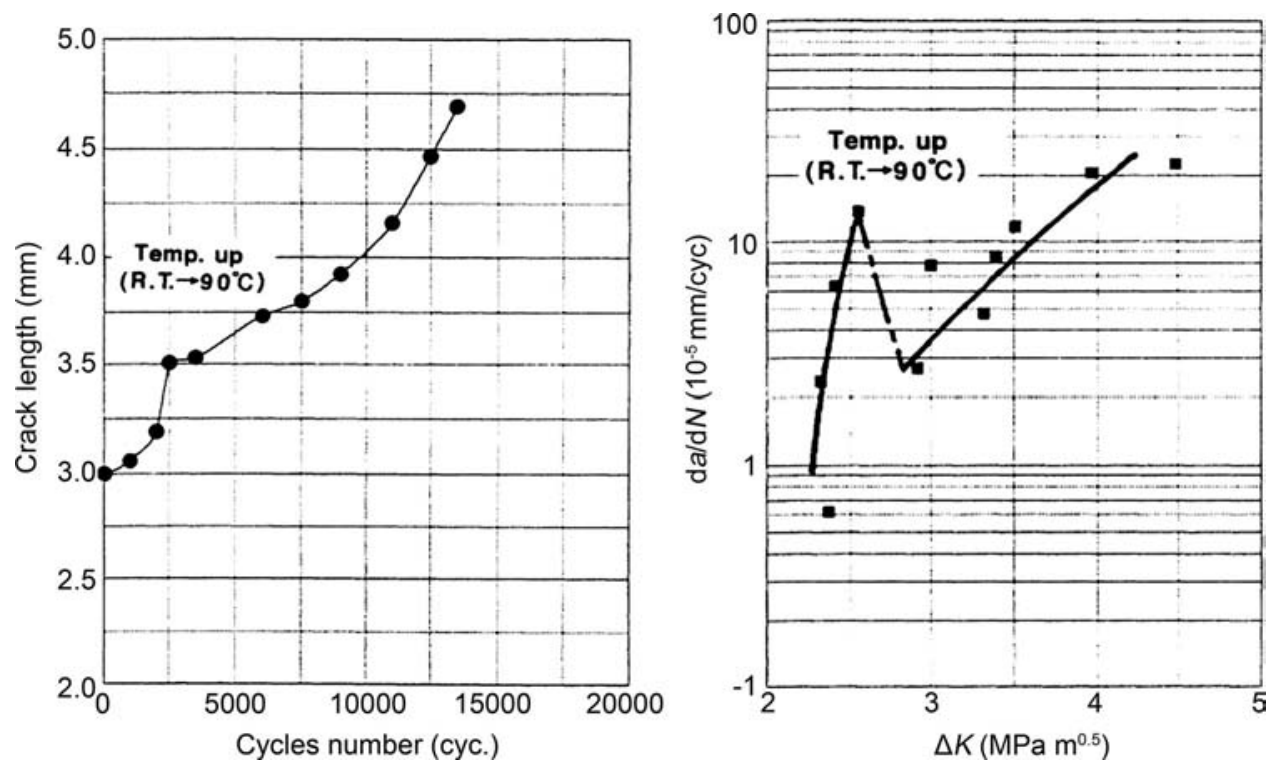

Fig. 35 Correlation of crack length $(a)$ versus cyclic number $(N)$ a, crack propagation rate $(\mathrm{d} a / \mathrm{d} N)$ versus apparent stress intensity factor range $(\Delta K)$ b in $\mathrm{NiTi}_{\mathrm{f}} / \mathrm{Al}$ specimen (3 vol\% $\mathrm{NiTi}_{\mathrm{f}}$, without prestrain) before and after the increase of temperature from room temperature (R.T.) to $90{ }^{\circ} \mathrm{C}\left(>A_{\mathrm{f}}\right)[19]$
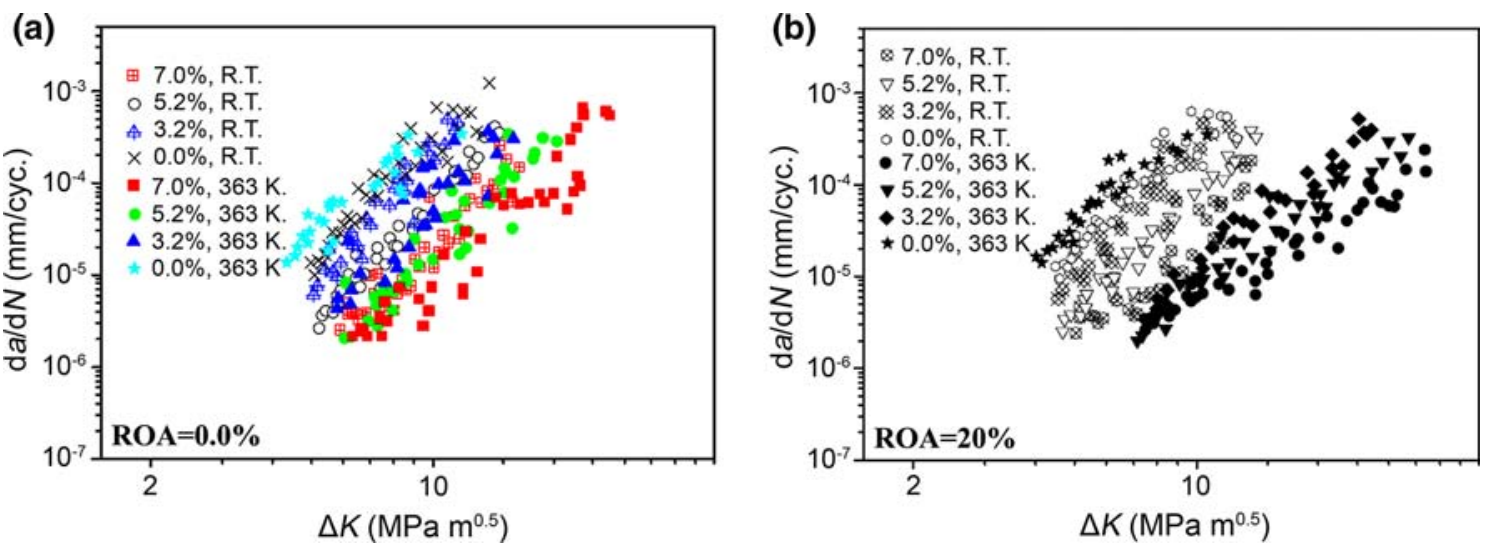

Fig. 36 Relationship between the crack growth rate and stress intensity factor $\Delta K$ at room temperature and $363 \mathrm{~K}$ (volume fractions of NiTi $\mathrm{f}_{\mathrm{f}}$ are $0.0,3.2,5.2$ and $7.0 \%$ ): $\mathbf{a} \mathrm{ROA}=0.0 \%$; $\mathbf{b} \mathrm{ROA}=20 \%[38]$

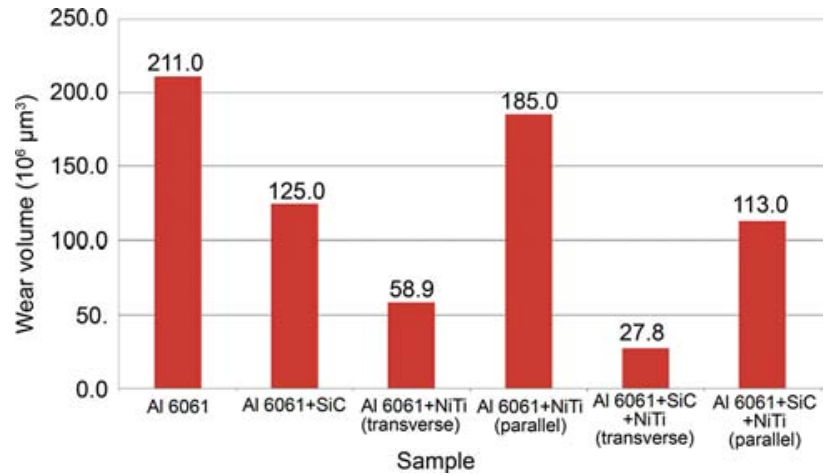

Fig. 37 Wear volume of various samples [51]

\section{Concluding Remarks}

In this review article, current developments in the fabrication method, microstructure, interface reaction, physical and mechanical properties, modeling and simulation of MMCs reinforced with SMA have been addressed. As a result, the following conclusions can be drawn:

Most efforts on SMA/metal composites have been put on the AMCs especially the long SMA fiber-reinforced AMCs so far. In addition to Al matrix, other metal matrices, such as magnesium and titanium, and In alloys attract more and more research interesting. 
The existence of the interfacial diffusion and/or reaction layer is a chemical result between the matrix and fiber and is very important information in the adhesion state of the interface. A properly designed interface layer is very important for achieving the composites with good physical and mechanical properties. Therefore, interface design will still be the key issue of SMA/metal composites.

Concerning the interfacial design, it mainly depends on the proper fabrication methods with a pertinent process temperature and time. As a result, new fabrication methods which may control the interface reaction and elemental diffusion, i.e., with relatively low processing temperature and short duration time, do deserve more attention.

The mechanisms of shape memory effect on the thermal-mechanical properties of the composites need to be further investigated. The phase stability, aging or degradation, and transformation hysteresis under particular constraints are not well understood so far. A proper prestrain process is beneficial for improving the transformation behavior of the embedded SMA reinforcements, so as to increase physical and mechanical properties of the composite.

Acknowledgments This work was financially supported by the National Natural Science Foundation of China (Nos. 51101155 and 51331008) and the National Basic Research Program of China (No. 2012CB619600).

\section{References}

[1] I.A. Ibrahim, F.A. Mohamed, E.J. Lavernia, J. Mater. Sci. 26, 1137 (1991)

[2] V.K. Lindroos, M.J. Talvitie, J. Mater. Process. Technol. 53, 273 (1995)

[3] S.C. Tjong, Z.Y. Ma, Mater. Sci. Eng., R 29, 49 (2000)

[4] L. Janke, C. Czaderski, M. Motavalli, J. Ruth. Mater. Struct. 38, 578 (2005)

[5] J. Mohd Jani, M. Leary, A. Subic, M.A. Gibson, Mater. Des. 56, 1078 (2014)

[6] M. Zarinejad, Y. Liu, Adv. Funct. Mater. 18, 2789 (2008)

[7] W.Y. Ni, Y.T. Cheng, D.S. Grummon, Appl. Phys. Lett. 82, 2811 (2003)

[8] Y.J. Zheng, L.S. Cui, J. Schrooten, Appl. Phys. Lett. 84, 31 (2004)

[9] K. Otsuka, C.M. Wayman, Shape Memory Materials (Cambridge University Press, Cambridge, 1998)

[10] V. Michaud, Scr. Mater. 50, 249 (2004)

[11] D.Z. Yang, Mater. Desi. 21, 503 (2000)

[12] Z.G. Wei, R. Sandström, S. Miyazaki, J. Mater. Sci. 33, 3763 (1998)

[13] J. Schrooten, V. Michaud, J. Parthenios, G.C. Psarras, C. Galiotis, R. Gotthardt, J.A. Manson, J. Van Humbeeck, Mater. Trans. 43, 961 (2002)

[14] S.L. Angioni, M. Meo, A. Foreman, Smart Mater. Struct. 20, 1 (2011)

[15] M. Taya, Mater. Trans. 32, 1 (1991)

[16] M. Taya, S. Hayashi, A.S. Kobayashi, H.S. Yoon, J. Am. Ceram. Soc. 73, 1382 (1990)
[17] Z.G. Wei, C.Y. Tang, W.B. Lee, J. Mater. Process. Technol. 69, 68 (1997)

[18] Y. Furuya, A. Sasaki, M. Taya, Mater. Trans. 34, 224 (1993)

[19] Y. Furuya, J. Intel, Mater. Sys. Struct. 7, 321 (1996)

[20] Y. Yamada, M. Taya, R. Watanabe, Mater. Trans. 34, 254 (1993)

[21] Y. Yamada, R. Watanabe, in THERMEC'97, International Conference on Thermomechanical Processing of Steels and Other Materials, University of Wollongong, Wollongong, 7-11 July 1997

[22] M. Taya, Y. Furuya, Y. Yamada, R. Watanabe, S. Shibata, T. Mori, in North American Conference on Smart Structures and Materials, Albuquerque, 1-4 Feb 1993

[23] C. Han, I. Choi, K. Cho, I. Park, Met. Mater. 6, 169 (2000)

[24] J. Hu, Q. Zhang, G.H. Wu, Y. Liu, D.G. Li, Mater. Sci. Eng. A 597, 20 (2014)

[25] J. Hu, Q. Zhang, Y. Liu, G.H. Wu, J. Alloys Compd. 589, 491 (2014)

[26] W.D. Armstrong, H. Kino, J. Intel, Mater. Sys. Struct. 6, 809 (1995)

[27] W.D. Armstrong, H. Kino, in 1st US-Japan Workshop on Smart Materials and Structures, University of Washington, Seattle, 3-4 Dec 1995

[28] W.D. Armstrong, T. Lorentzen, Scr. Mater. 36, 1037 (1997)

[29] W.D. Armstrong, T. Lorentzen, P. BrØndsted, P.H. Larsen, Acta Mater. 46, 3455 (1998)

[30] W.D. Armstrong, T. Lorentzen, in Smart Structures and Materials 1999 Conference, Newport Beach, 1-4 Mar 1999

[31] W. D. Armstrong, P. G. Reinhall, in Smart Structures and Materials 2000 Conference, Newport Beach, 5-9 Mar 2000

[32] W.D. Armstrong, T. Lorentzen, Metall. Mater. Trans. A 33, 3535 (2002)

[33] T. Bannuru, W.D. Armstrong, Metall. Mater. Trans. A 35, 1403 (2004)

[34] W.D. Armstrong, T. Bannuru, in Smart Structures and Materials 2005 Conference, San Diego, 7-10 Mar 2005

[35] K. Hamada, J.H. Lee, K. Mizuuchi, M. Taya, K. Inoue, Metall. Mater. Trans. A 29, 1127 (1998)

[36] K. Mizuuchi, K. Hamada, M. Taya, K. Inoue, in $1^{\text {st }}$ US-Japan Workshop on Smart Materials and Structures, University of Washington, Seattle, 3-4 Dec 1996

[37] Y.C. Park, G.C. Lee, Y. Furuya, Mater. Trans. 45, 264 (2004)

[38] Y.C. Park, J.H. Kang, J.K. Lee, G.C. Lee, Y. Furuya, Smart Mater. Struct. 16, 982 (2007)

[39] Y.C. Park, Y.J. Jo, S.H. Baek, Y. Furuya, Smart Mater. Struct. 18, 055009 (2009)

[40] L.S. Cui, Y.J. Zheng, D. Zhu, D.Z. Yang, J. Mater. Sci. Lett. 19, 1115 (2000)

[41] Y.J. Zheng, L.S. Cui, D. Zhu, D.Z. Yang, Mater. Lett. 43, 91 (2000)

[42] Y.J. Zheng, L.S. Cui, Intermetallics 12, 1305 (2004)

[43] Y.J. Zheng, L.S. Cui, Y. Li, D.Z. Yang, J. Mater. Sci. Technol. 20, 390 (2004)

[44] C.Y. Kong, R.C. Soar, P.M. Dickens, Compos. Struct. 66, 421 (2004)

[45] C.Y. Kong, R.C. Soar, Mater. Sci. Eng., A 412, 12 (2005)

[46] R. Hahnlen, M.J. Dapino, in Conference on Industrial and Commercial Applications of Smart Structures Technologies 2011, San Diego, 7-8 March 2011

[47] R. Hahnlen, M.J. Dapino, in Conference on Behavior and Mechanics of Multifunctional Materials and Composites, San Diego, 12-15 March, 2012

[48] R. Hahnlen, M.J. Dapino, Compos. B 59, 101 (2014)

[49] K. Mizuuchi, K. Inoue, K. Hamada, M. Sugioka, M. Itami, Y. Okanda, M. Kawahara, in 5th European Conference on Smart Structures and Materials, Glasgow, 22-24 May 2000 
[50] C.L. Xie, M. Hailat, X. Wu, G. Newaz, M. Taya, B. Raju, J. Eng. Mater. Technol. 129, 69 (2007)

[51] O. Akalin, K.V. Ezirmik, M. Urgen, G.M. Newaz, J. Tribol. 132, 041603 (2010)

[52] Y. Liu, Metall. Mater. Trans. A 39, 2749 (2008)

[53] Z. Chaudhury, M. Hailat, Y. Liu, G. Newaz, J. Mater. Sci. 46, 1945 (2011)

[54] G. Miranda, O. Carvalho, F.S. Silva, D. Soares, J. Compos. Mater. 47, 1625 (2012)

[55] I.S. Ahn, T.H. Nam, S.R. Bae, Met. Mater. 3, 260 (1997)

[56] Z.G. Wei, C.Y. Tang, W.B. Lee, L.S. Cui, D.Z. Yang, Mater. Lett. 32, 313 (1997)

[57] G. Wang, P. Shi, M. Qi, J.J. Xu, F.X. Chen, D.Z. Yang, Metall. Mater. Trans. A 29, 1741 (1998)

[58] G.A. Porter, P.K. Liaw, T.N. Tiegs, K.H. Wu, JOM 52, 52 (2000)

[59] R.R. Thorat, D.D. Risanti, D. San Martín, G. Garces, P.E.J. Rivera Díaz del Castillo, S. van der Zwaag, J. Alloys Compd. 477, 307 (2009)

[60] D. San Martín, D.D. Risanti, G. Garces, P.E.J. Rivera Díaz del Castillo, S. van der Zwaag, Mater. Sci. Eng. A 526, 250 (2009)

[61] I.S. Ahn, S.Y. Bae, Y.Y. Kim, Metal. Mater. Int. 10, 39 (2004)

[62] M. Dixit, J.W. Newkirk, R.S. Mishra, Scr. Mater. 56, 541 (2007)

[63] D.R. Ni, J.J. Wang, Z.N. Zhou, Z.Y. Ma, J. Alloys Compd. 586, 368 (2014)

[64] R.S. Mishra, Z.Y. Ma, Mater. Sci. Eng., R 50, 1 (2005)

[65] Z.Y. Ma, Metall. Mater. Trans. A 39, 642 (2008)

[66] R.S. Mishra, Z.Y. Ma, I. Charit, Mater. Sci. Eng. A 341, 307 (2003)

[67] Y.X. Gan, D. Solomon, M. Reinbolt, Materials 3, 329 (2010)

[68] Y.S. Sato, M. Urata, H. Kokawa, Metall. Mater. Trans. A 33, 625 (2002)

[69] K. Mizuuchi, K. Inoue, K. Hamada, M. Sugioka, M. Itami, M. Fukusumi, M. Kawahara, Mater. Sci. Eng. A 367, 343 (2004)
[70] K. Mizuuchi, K. Inoue, M. Sugioka, M. Itami, K. Hamada, M. Kawahara, J. Jpn. Inst. Metal. 69, 608 (2005)

[71] B. Yan, G. Li, Composite A 36, 1590 (2005)

[72] D.S. Li, X.P. Zhang, Z.P. Xiong, Y.W. Mai, J. Alloys Compd. 490, L15 (2010)

[73] Z. Esen, Mater. Sci. Eng. A 558, 632 (2012)

[74] K. Mizuuchi, K. Inoue, K. Hamada, K. Yamauchi, K. Enami, M. Sugioka, M. Itami, Y. Okanda, Mater. Sci. Eng. A 329-331, 557 (2002)

[75] J. San Juan, M.L. NÓ, Mater. Sci. Eng., A 442, 429 (2006)

[76] G.A. López, M.L. Nó, E.H. Bocanegra, J. San Juan, M. Barrado, in International Conference on Shape Memory and Superelastic Technologies, Pacific Grove, 7-11 May 2006

[77] G.A. López, M. Barrado, J.M. San Juan, M.L. Nó, Mater. Sci. Eng. A 495, 304 (2008)

[78] G.A. López, M. Barrado, J. San Juan, M.L. Nó, Mater. Sci. Eng. A 521-522, 359 (2009)

[79] M. Barrado, G.A. López, M.L. Nó, J. San Juan, Mater. Sci. Eng. A 521-522, 363 (2009)

[80] W.D. Armstrong, J. Intel, Mater. Sys. Struct. 7, 448 (1996)

[81] W.D. Armstrong, T. Lorentzen, Int. J. Solid. Struct. 38, 7029 (2001)

[82] W.B. Lee, M. Jie, C.Y. Tang, J. Mater. Process. Technol. 116 , 219 (2001)

[83] D.C. Lagoudas, J.G. Boyd, Z. Bo, J. Eng. Mater. Technol. 116, 337 (1994)

[84] J.G. Boyd, D.C. Lagoudas, J. Int. Mater. Sys. Struct. 5, 333 (1994)

[85] J.G. Boyd, D.C. Lagoudas, Int. J. Plast. 12, 843 (1996)

[86] M. Cherkaoui, Q.P. Sun, G.Q. Song, Int. J. Solid. Struct. 37, 1577 (2000)

[87] G.Q. Song, Q.P. Sun, Smart Mater. Struct. 9, 693 (2000)

[88] J.K. Lee, M. Taya, Scr. Mater. 51, 443 (2004)

[89] J.K. Lee, G.D. Kim, J. Mech. Sci. Technol. 19, 1460 (2005)

[90] Y. Freed, J. Aboudi, Int. J. Solid. Struct. 46, 1634 (2009) 